\title{
Do Behavioral Biases Affect Prices?
}

\author{
JOSHUA D. COVAL and TYLER SHUMWAY*
}

\begin{abstract}
This paper documents strong evidence for behavioral biases among Chicago Board of Trade proprietary traders and investigates the effect these biases have on prices. Our traders appear highly loss-averse, regularly assuming above-average afternoon risk to recover from morning losses. This behavior has important short-term consequences for afternoon prices, as losing traders actively purchase contracts at higher prices and sell contracts at lower prices than those that prevailed previously. However, the market appears to distinguish these risk-seeking trades from informed trading. Prices set by loss-averse traders are reversed significantly more quickly than those set by unbiased traders.
\end{abstract}

A NUMBER OF RECENT PAPERS in the finance literature have proposed behavioral theories to account for asset pricing anomalies. ${ }^{1}$ To provide support for their models' assumptions about investor behavior, these papers draw heavily on the experimental psychology literature, in which evidence of cognitive biases is abundant. On the one hand, behavioralists contend that this evidence has been important in prompting researchers to consider heterodox explanations of market anomalies. On the other hand, skeptics argue that there exists so much of such evidence that behavioralists can "psycho-mine" the experimental psychology literature to find support for the particular set of assumptions that allow their models to match otherwise anomalous data. Contributing to the skeptics' argument, many of the behavioral theories rely on biases that are quite different from each other and often produce opposite conclusions about investor behavior. Not surprisingly, strong demand has emerged for empirical work that identifies which of the biases, if any, influences investor decisions. Even stronger is the demand to determine whether these biases are merely a

*Joshua D. Coval is at the Harvard Business School and Tyler Shumway is at University of Michigan Business School, respectively. This research is supported by the NTT fellowship of the Mitsui Life Center. We are grateful to Sugato Battacharyya, George Benston, Jonathan Berk, Hank Bessembinder, Jonathan Karpoff, Roni Michaely, Lubos Pastor, Matt Spiegel, Mark Taranto, Dick Thaler, Tuomo Vuolteenaho, Ivo Welch, George Wu, seminar participants at Berkeley, Chicago, Cincinnati, Cornell, Duke, Emory, HBS, Indiana, Michigan, North Carolina, Stanford, Wharton, Yale, the 2001 Meetings of the Western Finance Association in Tucson, the editor Rick Green, and an anonymous referee for helpful comments and suggestions. We also thank Steven J. Cho of the CFTC for helping us obtain the data used for this study.

${ }^{1}$ Examples include theories of overconfidence (Barberis, Shleifer, and Vishny (1998), Daniel, Hirshleifer, and Subrahmanyam (1998), and Odean (1998b)), loss aversion (Benartzi and Thaler (1995), Shumway (1998), and Barberis and Huang (2001)), and the house-money effect (Barberis, Huang, and Santos (2001)). 
curious aspect of certain market participants' behavior or whether they have important consequences for prices. This paper supplies evidence about both of these issues.

Empirical tests of behavioral models face a number of challenges. First, the models cannot be easily tested with aggregate data. As noted by Campbell (2000), "[Behavioral models] cannot be tested using aggregate consumption or the market portfolio because rational utility-maximizing investors neither consume aggregate consumption (some is accounted for by nonstandard investors) nor hold the market portfolio (instead they shift in and out of the stock market)" (p. 1551). As a result, testing behavioral models is quite difficult without detailed information on the trading behavior of market participants. Unfortunately, given the issues of confidentiality associated with such data, availability of such information is generally quite low. An additional difficulty is that an investor's horizon, while highly ambiguous in most empirical settings, represents a key dimension in behavioral models. For instance, when fund managers are averse to losses, it is not clear whether their aversion relates to returns at the monthly, quarterly, or annual horizons, or even whether they view losses on positions taken recently as equivalent to losses on positions entered into years ago. Finally, even if biases can be identified in investor behavior, to demonstrate that this is more than just instances of noise trading, empirical tests must be positioned to identify a link between biases in individual trader behavior and overall prices. $^{2}$

In this paper, we conduct a series of tests to determine the importance of behavioral biases in the price-setting process. Our tests focus on the trading behavior of market makers in the Treasury Bond futures contract at the Chicago Board of Trade (CBOT). This environment offers a number of unique advantages in assessing behavioral biases and any consequences they might have for prices.

First, since each of the traders we study trades on the order of $\$ 200$ million worth of contracts per day, and, as a group, take part in over $95 \%$ of all trades, any biases in their trading behavior have a reasonable prospect of showing up in prices. While several papers have uncovered evidence of behavioral biases in the trading activity of various sets of investors, almost no evidence exists for biases in investor behavior when significant amounts of capital are on the line. ${ }^{3}$ Thus, if behavioral biases are suspected of playing a price-setting role in large, liquid capital markets, then only an examination of traders that transact with significant capital at stake is likely to yield evidence thereof. The idea that professional traders may play an important role in distorting asset prices in large capital markets has been argued, most recently, by Allen (2001).

\footnotetext{
${ }^{2}$ Odean (1999), who studies transaction data for clients of a large discount brokerage and uncovers strong and widespread evidence of overconfidence, offers an important start in this direction. A key question raised by the findings is whether the individuals' overconfident behavior impacts prices.

${ }^{3}$ For example, the overconfident investors studied by Odean (1999) place, on average, 1.4 trades per year worth around $\$ 11,000$ each.
} 
A second benefit of our setting is that, because we begin with every transaction made by the market makers in the T-Bond pit over a 1-year period (over 5 million transactions), we have significant power to detect biases in trading behavior. This power is aided by the fact that our traders are full-time proprietary traders trading on personal accounts, whose behavior is therefore undistorted by agency or career concerns issues, who are not trading to satisfy hedging needs, and whose livelihood depends entirely on their ability to trade effectively. Because our traders are market makers, and do not trade through brokers or other intermediaries, they are far more proximate to the price-setting process. As a result, relative to other market participants, any impact their trading biases have on prices is likely to be more pronounced and therefore easier to detect.

The final benefit of our focus on CBOT market makers is that the relevant horizon is quite clear. While in most settings the horizon over which investor performance is evaluated is ambiguous, CBOT market makers have clear incentives and mechanisms encouraging them to evaluate their performance on a daily basis. The traders receive and review statements at the end of each trading day detailing their performance during the day. Because most trades are unwound by the end of the day, and traders seldom retain significant positions overnight, all profits or losses during a day can be attributed to trades executed on that particular day. Since the market makers' focus is on reading the order flow, which conveys highly short-lived signals regarding future trading activity, they carry little informational advantage from one day to the next. As a result, the statements CBOT market makers receive at the close of the trading day can be viewed as perfect report cards on their day at work.

Our study tests the null hypothesis of standard, rational investor behavior against a number of popular, though potentially competing, alternative behavioral hypotheses, including self-attribution bias, representativeness bias, the house-money effect, and loss aversion. We argue that if traders overly attribute past trading success to their own ability, if traders view past trading profits as overly representative of future trading opportunities, or if traders are more willing to assume risk when gambling with the "house's money," they will take greater risks as their profits grow. If traders are averse to losses incurred at the daily horizon, this will lead to the opposite result: Traders will take fewer risks as they become profitable. Our setting allows us to study self-attribution bias, representativeness bias, and the house-money effect on the one hand, and loss aversion on the other, in an environment in which they yield opposite predictions regarding the relationship between realized profits and subsequent risk-taking.

To examine this relationship, we simply split the trading day into two periods and test whether traders with profitable mornings increase or reduce their afternoon risk-taking. We find strong evidence that CBOT traders are highly loss averse: They are far more likely to take on additional afternoon risk following morning losses than following morning gains. In our sample, a trader with morning losses has a $31.2 \%$ chance of taking above-average risk in the afternoon, compared to a trader who earns a profit in the morning, who has only a 
$27.0 \%$ chance. Thus, a losing trader is $15.5 \%$ more likely to take above-average afternoon risk than a winning trader. This result shows up robustly across most of our tests, including pooled OLS regressions, panel regressions, and Fama-MacBeth style averages of trader-by-trader (time series) or day-by-day (cross-sectional) regression coefficients. The result is also robust to employing alternate measures of risk: Losing traders are $17.4 \%$ more likely to place an above-average number of afternoon trades and are $9.5 \%$ more likely to trade at above-average sizes.

Next, to see whether the traders' loss aversion has an impact on prices, we examine whether our traders are more likely to move afternoon prices following morning losses. Although the T-Bond market makers typically wait for other traders to take the other side of their bid or offer (and thereby gain an edge relative to other market participants), they will on occasion take the other side of the bid or offer of other traders and thereby move the price. Specifically, we identify traders as "marginal" or "price-setting" if they purchase at a higher price or sell at a lower price than prevailed previously. For instance, if the previous trade took place at 25 , we identify a given market maker as the marginal trader if he purchases at 26 or if he sells at 24 . Our results clearly demonstrate that traders are more likely to place such price-moving trades following morning losses. A trader who loses money in the morning is around $15 \%$ more likely to execute such a trade than a trader who makes money in the morning. Overall, while traders lose money $32.9 \%$ of the time, losing traders account for $38 \%$ of all afternoon price-setting trades placed by market makers.

To gauge the quality of prices set by traders with morning losses and to assess how permanently they move prices, we monitor the average price change that follows a price-setting trade. If the marginal prices set by losing traders persist for a significant period of time, their loss-averse behavior may have permanent consequences for prices. If the prices do not revert quickly, it suggests that such trading is not so costly to the loss-averse traders-i.e. they are able to create their own space. ${ }^{4}$ If, on the other hand, prices revert strongly to previous levels, this raises doubts about the potential importance of loss aversion in influencing prices over the longer term. The magnitude of the reversal in prices set by losing traders offers a measure of the costs associated with their loss-averse behavior. Our results indicate significant reversals of price changes made by loss-averse traders. During the 5 minutes following a price-setting trade, a trader attempting to take on additional risk sees prices revert $27 \%$ more if he experienced morning losses than if he experienced gains. This suggests that the price-setting trades of locals with morning losses have far less permanent an influence than the average price-setting local trade. This finding is consistent with the arguments made by Friedman (1953) and Fama (1965) against the importance of noise traders in the price formation process.

\footnotetext{
${ }^{4}$ This relates to studies investigating the long-run survival of noise traders, such as De Long et al. (1990), who demonstrate that noise traders can create risk that is priced and prosper in assuming this risk.
} 
Our final set of results examines whether prices exhibit greater volatility on afternoons that follow mornings when trader losses are widespread. This inquiry is closely related to the work of Shiller (1981, 1989), who attributes excess volatility in asset prices to patterns in human behavior. Consistent with the above results, our evidence suggests that loss aversion helps account for the short-term volatility of afternoon prices, but cannot account for volatility measured over longer horizons. Following mornings during which overall losses are one standard deviation larger than usual, expected afternoon volatility measured at the 1-second frequency increases by $11.5 \%$. As volatility is measured over longer periods, however, the effect of morning losses disappears. For instance, at the 10-minute horizon, the increase in expected volatility drops to $6.4 \%$ and loses statistical significance. However, our volatility results are not entirely conclusive, since we do not have a sufficiently long time series to explore the volatility hypothesis with much power.

The paper proceeds as follows. In Section I, we discuss a variety of behavioral biases and their implications for the daily horizon trade setting. In Section II, we outline our data and tests. Section III presents the results of our tests for the existence of behavioral biases among CBOT traders. Section IV examines the price impact of the biases identified in Section III, and Section V concludes.

\section{Behavioral Biases among Professional Traders}

To explain deviations from market efficiency, behavioral models must take a stand on what form of irrationality is behind investor behavior. For guidance, they often turn to evidence from the experimental psychology literature. This has led to the employment of a wide variety of biases in behavioral finance theory (see Barberis and Thaler (2003) or Hirshleifer (2001) for reviews of the literature). Following Barberis and Thaler (2003), we can classify these deviations from rationality as either biases in beliefs or biases in preferences. Since our study examines deviations from rationality by focusing on the relationship between profits and subsequent risk-taking activity across the trading day, it is worth identifying what predictions various biases in beliefs or preferences that have been employed in the literature yield for our setting.

\section{A. Biases in Beliefs}

As CBOT market makers trade, beliefs emerge as they interpret a variety of private signals related to the pit order flow. How profitably market makers trade in response to these signals, by adjusting their quotes and managing their positions, depends both on their interpretation of the signals and on luck. Profits and subsequent risk-taking activity may be related across the trading day if signal quality varies in a predictable way from day to day. In particular, if certain days have above-average signal quality, market makers might rationally decide to take more risk than usual following profitable mornings.

However, biases in beliefs emerge across the trading day if market makers systematically misinterpret these signals. One bias that has been employed in 
the literature is that of self-attribution (e.g., Daniel et al. (1998) and Gervais and Odean (2001)). A number of papers in experimental psychology, including Langer and Roth (1975) and Miller and Ross (1975), document that people take credit for past success and attribute past failure to bad luck. In our setting, if traders exhibit biased self-attribution, a trader who executes profitable trades becomes overconfident in his ability to interpret the order flow signals. Such a trader overly attributes the profits of his trades to his interpretation of the order flow signals and insufficiently attributes the profits to luck, taking more risk when his recent trades have been profitable. ${ }^{5}$

A second set of biases in beliefs that have been employed in the literature is that of representativeness and conservativeness. Experimental psychologists find that people tend to rely too heavily on small samples (to view them as overly representative of the underlying population) and rely too little on large samples (to update their priors too conservatively). ${ }^{6}$ Barberis et al. (1998) model investor sentiment in a setting in which investors at times overweight new information relative to priors (representativeness) and at times underweight new information (conservativeness). In our setting, if traders afflicted with a representativeness bias view morning trading conditions as overly reflective of those they can expect to face in the afternoon, profitable mornings are followed by amplified afternoon risk-taking. Conservativeness bias, on the other hand, attenuates any positive relation between morning profits and afternoon risktaking, should one exist.

Thus, in our setting, both rational beliefs and beliefs with biases may lead to a positive relation between profits and subsequent risk-taking. However, other than the presence of (or belief in) extreme negative autocorrelation in profit opportunities, beliefs are unlikely to yield a negative relation between profits and subsequent risk-taking.

\section{B. Biases in Preferences}

The literature has also employed preference-based deviations from rationality. Most of these are based on the prospect theory of Kahneman and Tversky (1979), where utility functions are derived as convex in the region of losses, kinked at zero, and concave in the region of gains. From this theory, a variety of biases emerge relative to individuals whose behavior is consistent with the Von Neumann-Morgenstern axioms.

Perhaps the most salient feature of prospect theory is that of extreme risk aversion in the neighborhood of zero. ${ }^{7}$ Benartzi and Thaler (1995) and Barberis et al. (2001) model the behavior of a representative investor with such preferences and generate implications that help account for the equity premium

\footnotetext{
${ }^{5}$ However, in the Gervais and Odean (2001) model, self-attribution bias tends to attenuate with experience. Thus, there may be reasons to expect the degree of self-attribution bias among a set of professional traders to be modest.

${ }^{6}$ See, e.g., Tversky and Kahneman $(1971,1974)$ and Kahneman and Tversky (1973).

${ }^{7}$ Using experimental data, Kahneman and Tversky (1992) estimate the slope below zero to be 2.25 times that above zero.
} 
puzzle. For a trader whose utility is a function of daily gains or losses, a kink at zero implies that profits near zero will lead to extremely high subsequent risk aversion.

A second aspect of prospect theory is that of risk-seeking behavior in the region of losses. Kahneman and Tversky (1979) characterize such behavior in the following terms, " $[\mathrm{A}]$ person who has not made peace with his losses is likely to accept gambles that would be unacceptable to him otherwise" (p. 287). ${ }^{8}$ In our setting, this suggests that traders who have experienced losses are most inclined to take subsequent risks. Conversely, traders with profitable mornings reduce their exposure to afternoon risk.

However, not all biases in preferences predict a negative relation. The housemoney effect, documented in Thaler and Johnson (1990), finds that individuals have increasing risk tolerance as their wealth exceeds the reference point. ${ }^{9}$ The house-money effect is employed by Barberis et al. (2001), who model investors as becoming more risk tolerant when their risky asset holdings earn returns that exceed a historical benchmark. In our setting, traders who have earned profits in the morning that exceed some benchmark level become less risk averse in the afternoon because they feel they are "gambling with the house money." Thus, biases in preferences can predict either a positive or a negative relation between profits and subsequent risk-taking.

\section{Identifying Behavioral Biases}

While none of the behavioral biases that we consider has been documented among professional market makers, it seems plausible that these professionals might exhibit any or all of these characteristics. If traders do exhibit multiple biases, our tests will help us determine which biases are the most economically significant. For example, it is plausible that market makers exhibit both loss aversion and the house-money effect, but that the benchmark level above which the house-money effect is important is sufficiently high that loss aversion is much easier to detect in the data.

Moreover, as Barberis and Thaler (2003) note, in testing behavioral theories, identifying the appropriate horizon is critical. A mismatch between the horizon used by investors to evaluate their performance and that assumed in a test design may result in failure to detect biases present in the data. In experimental psychology, most of the important findings of irrationality are documented over extremely short horizons-subjects are rarely tested for more than a single day. In the finance literature, behavioral assumptions have been employed to account for both short- and long-horizon investor behavior. As discussed above, we view a 1-day horizon to be most relevant for our set of traders—they receive

\footnotetext{
${ }^{8}$ ESPN's Bill Simmons offers the following analogy: "Hey, did you notice that the Red Sox picked up Tony Clark (and his $\$ 7$ million contract) off waivers last week? [Red Sox GM] Dan Duquette is like a blackjack player who's down $\$ 700$ and realizes that he has to leave the casino in 20 minutes, so he starts making $\$ 100$ bets" (11/03/01).

${ }^{9}$ Thaler and Johnson (1990) argue that whether individuals exhibit risk-seeking over losses or house money depends on how they edit and encode the gambles that they consider.
} 
statements to evaluate their performance at the end of each day, they generally enter the trading day with no outstanding positions, and they evaluate signals that are unlikely to be useful across trading days. However, it is important to note that biases relevant over longer horizons may not be detected by our tests.

It is also important to note that there are several ways that preferences consistent with expected utility theory can deliver a relation between profits and subsequent risk-taking. First, if wealth effects are important-i.e., if morning gains and losses significantly alter the local curvature of our traders' indirect utility functions-and if traders have declining absolute risk aversion, then traders that have become notably wealthier from morning trading become less risk-averse in the afternoon.

Second, if margin constraints are important, morning profits influence the amount of risk traders are willing and/or allowed to take in the afternoon. Traders who find themselves near their margin constraint following a losing morning may be inclined to reduce their risk-taking to avoid a margin call. Conversely, traders who are below their margin constraint may be inclined to increase their afternoon risk-taking to get above the margin constraint before they are forced to liquidate.

Finally, if career or reputation concerns are important to our traders, their conditional risk-taking across the trading day is likely to resemble that of mutual fund managers across the calendar year, as documented by Chevalier and Ellison (1997). They find that mutual fund managers who have underperformed the market through the third quarter of a given year will face a convex relationship between their fourth quarter performance and the net flow of capital into their mutual fund during the subsequent year. For managers who have outperformed, the relationship is concave. Chevalier and Ellison then demonstrate that the fund managers respond appropriately to these incentives-they increase the riskiness of their portfolios if they are underperforming and they lower the riskiness of their portfolios if they are outperforming. To the extent that traders are compensated in a similar nonlinear way as a function of their daily trading profits, one might expect them to exhibit increased afternoon risk-taking following losing mornings and to lower their afternoon risk-taking following profitable mornings. To mitigate the potential effects of such agency considerations, our tests are conducted solely using traders who trade on their own personal accounts. In this way, our focus is on traders whose daily compensation corresponds exactly to their net gain or loss from trading each day.

To summarize, our null hypothesis is that afternoon risk is unrelated to morning profits. If markets are efficient, traders are rational, traders have Von Neumann-Morgenstern utility functions, and wealth effects are negligible, margin constraints are unimportant, traders' compensation and reputational concerns are neutral, and profit opportunities are uncorrelated across the trading day, then we should expect no relationship between morning returns and afternoon risk-taking. Self-attribution bias, the representativeness heuristic, and the house-money effect all generate an alternative hypothesis on one side of the null: that morning returns will be positively related to afternoon risk-taking. Risk-seeking in losses predicts the null will be rejected in the 
other direction: that morning returns will be negatively related to afternoon risk-taking.

\section{Data and Method}

Our primary data consist of the entire history of transactions (audit trail data) from the CBOT T-Bond futures pit during all of $1998 .{ }^{10}$ The data include identifiers for the buying trader and the selling trader, the price, and the time for each transaction. They also include a code indicating whether each trade is performed on behalf of a customer, on behalf of the trader's clearing firm, on behalf of another trader, or for a trader's personal account. Our data include records of over five million futures transactions, $97.4 \%$ of which involve frontmonth contracts, which are the focus of our tests. In $96.6 \%$ of the front-month futures transactions in our data, at least one of the two traders is trading on his personal account. There are 1,082 different traders in the data. Looking at how frequently each trader trades for his own account, we identify 426 local traders. Each of our locals executes at least 1,500 trades for his personal account, and trades bond futures on at least 100 days over the course of the year. We track each local's trades placed on their personal account and the associated inventories and profits throughout each trading session.

Since our hypotheses relate the risk that a trader takes to his profitability, it is important for us to measure both profits and risks correctly. To measure each trader's profits and inventory, we assume that each trader closes out his positions at the end of each day and thus begins each day with no position. This assumption is supported by the evidence of Kolb (1991), Kuserk and Locke (1993), and Manaster and Mann (1996), and has been used previously in Manaster and Mann, and Coval and Shumway (2001). As Manaster and Mann point out, since traders carry little overnight informational advantage, substantial overnight margin funding costs typically discourage them from carrying overnight positions. Of course, some noise is present in our calculations to the extent that traders close out positions during evening trading sessions, hedge their positions using options contracts, ${ }^{11}$ or place their trades through other locals. ${ }^{12}$ Assuming that there is no beginning inventory makes profit calculations simple. We multiply the difference between purchase and sales prices by quantities to arrive at a profit figure for each local at each point in time. However, to the extent that we have errors in our inventory measures, they tend to accumulate across the trading day. To account for this possibility, we put inventory controls in most of our regressions and we Winsorize all variables that depend on inventory at the $1^{\text {st }}$ and $99^{\text {th }}$ percentile levels. ${ }^{13}$ Since our hypotheses require us to

\footnotetext{
${ }^{10}$ The data was obtained from the CFTC via a Freedom of Information Act filing.

11 Though, as Manaster and Mann note, such activity is rare.

${ }^{12}$ Overall, on about $65 \%$ of our trader-day observations, the trader appears to finish the day trading session with an absolute inventory of 10 contracts or less. However, the ability of one trader to trade on behalf of another trader makes it difficult to calculate this number precisely.

${ }^{13}$ That is, all observations of variables depending on inventory that are in the $1^{\text {st }}$ or $99^{\text {th }}$ percentiles are set to the level of the $1^{\text {st }}$ and $99^{\text {th }}$ percentile cutoffs, respectively.
} 
have a profit figure available at a particular time each day, we add the market value of any inventory, calculated as the current price times the contracts outstanding, and add this to each local's running profit figure to generate a total profit variable for any time of the day.

Measuring the risk each trader takes is less straightforward. Certainly the number of trades a trader places and the average size of these trades is related to risk he assumes. However, since the level of risk in the T-Bond contract is nonconstant across the trading day, estimating each trader's risk requires an estimate of the risk a given position exposes the trader to at different points during a particular day. Therefore, we use historical price change data to model the level of risk throughout the trading day. Using second-by-second price data (time and sales data) from the Futures Industry Institute Data Center, we calculate the front-month futures contract price at the beginning of each minute of each day from 1989 to 1998 . These prices are used to calculate the absolute price change from one minute to the next.

To measure the risk a given position faces during the trading day, we employ an ordered logit regression (as in Coval and Shumway (2001)). A logit function of the probability of various potential absolute price changes over the next minute is regressed on the magnitude of price changes in the preceding 5 minutes and time-of-day dummy variables for each 5 -minute period during the trading day. The fitted values from this regression are then used to construct an expected absolute price change for each minute of each full trading day in 1998. Since our risk measure is an expected absolute price change, it roughly corresponds to a one standard deviation measure of price change risk associated with each 1-minute interval.

Finally, a trader's risk is calculated by multiplying each minute's risk measure by the trader's position at the beginning of the minute, and adjusting the trader's risk for the minute by any changes in inventory, and therefore risk, that occur during the minute. Again, our measure is roughly the standard deviation of wealth the trader assumed during a given minute. We then can calculate the cumulative risk a trader has assumed up to a given point each day by summing the measure of risk across all of the previous minutes. We term this risk measure the total dollar risk. Although we view this to be the proper way to measure trader-specific risk, we verify that our results are robust to employing alternative risk measures, such as number of trades and average trade size.

\section{Evidence of Behavioral Biases}

This section details the evidence we obtain from our first hypothesis, that locals at the CBOT exhibit behavioral biases. In particular, we examine the relationship between each trader's profits in the morning and the risk that he takes in the afternoon. If profit opportunities are uncorrelated across the trading day and wealth effects are negligible, any relationship between morning profits and afternoon risk-taking indicates that traders exhibit behavioral biases. 


\section{A. Summary Statistics}

To examine whether CBOT locals exhibit loss aversion, we look at the relation between morning trading performance and afternoon risk-taking. Since the trading day at the CBOT begins at 7:20 a.m. and ends at 2:00 p.m., we split the trading day into a morning period before 11:00 a.m. and an afternoon period after 11:00 a.m. We round the midway point of the trading day (10:40 a.m.) to 11 a.m. because it is somewhat closer to the midway point of the average trader's lunch break. Then, for each trader, we calculate morning and afternoon profits, and calculate morning and afternoon values for each of the three risk measures: total dollar risk, number of trades, and average trade size. With morning and afternoon profits and risks defined, we are almost ready to test our hypotheses.

We can examine our first hypothesis simply by relating the risk a trader takes in the afternoon to the trader's profit or loss in the morning. However, because traders face margin constraints, results from simple regressions may be misleading. If traders who experience large morning losses face binding margin constraints, they may be forced to liquidate their holdings and assume very little risk in the afternoon. Alternatively, if traders lose enough to trigger constraints, but their trading is not immediately restricted, they may take an inordinate amount of risk in hope that they can win back enough to avoid margin calls.

To control for trader heterogeneity with respect to margin constraints and risk tolerance in general, we normalize trader profits and risk-taking. To calculate a given trader's normalized morning profit, we first calculate the standard deviation of the trader's morning profits across all days of the sample and then divide each of the trader's morning profit observations by his profit standard deviation. We denote our measure of the normalized morning profits of trader $i$ on date $t$ as $\pi_{i, t}^{\mathrm{M}}$. We conduct the same calculation to normalize traders' afternoon profits, $\pi_{i, t}^{\mathrm{A}}$. We perform a similar calculation to normalize each trader's morning and afternoon risk. We calculate trader-specific means and standard deviations for each of our risk measures across the mornings and afternoons of our sample. We then demean each trader's daily morning and afternoon risk and divide them by their respective trader-specific standard deviations. We denote trader $i$ 's normalized measure of afternoon risk on date $t$ as $\operatorname{Risk}_{i, t}^{\mathrm{A}}$, where $\operatorname{Risk}_{i, t}^{\mathrm{A}}$ may be used to reflect trader $i$ 's total dollar risk, total number of trades, or average trade size on date $t$. Trader $i$ 's normalized morning risk is denoted as $\operatorname{Risk}_{i, t}^{\mathrm{M}}$. In this way, our profit measure and our three risk measures have standard deviations of one for each trader during both the morning and the afternoon. Although normalizations of trader profits and risk-taking are not required for most of our results, because they control for heterogeneity across traders, they allow for a more sensible economic interpretation of the results. ${ }^{14}$

\footnotetext{
${ }^{14}$ For instance, a $\$ 5,000$ morning loss means very different things to a trader who has never lost more than $\$ 1,000$ in a single day than to one who regularly experiences $\$ 5,000$ swings in his account.
} 
Table I

\section{Summary Statistics}

This table reports a number of summary statistics for the sample. The sample consists of the trading experience of 426 local traders at the CBOT's Treasury Bond Futures pit over 236 full trading days during 1998. Summary statistics using raw trader data are reported for all trader days. Trader data is normalized by trader for summary statistics of traders with profitable and losing mornings.

\begin{tabular}{|c|c|c|c|c|c|c|}
\hline \multicolumn{7}{|c|}{ Panel A: Statistics by Trader-Day } \\
\hline \multirow[b]{2}{*}{ Variable } & \multicolumn{3}{|c|}{ Morning } & \multicolumn{3}{|c|}{ Afternoon } \\
\hline & Mean & Median & St. Dev. & Mean & Median & St. Dev. \\
\hline \multicolumn{7}{|c|}{ All Trader-Days $(N=82,595)$ Raw Data } \\
\hline Profits & 1808.33 & 750.00 & 171848.13 & 661.78 & 187.50 & 113964.28 \\
\hline Number of trades & 116.62 & 88.00 & 105.37 & 73.25 & 52.00 & 72.95 \\
\hline Average trade size & 10.03 & 4.84 & 19.17 & 9.35 & 4.53 & 18.27 \\
\hline Total dollar risk & 9641.46 & 1150.00 & 57540.27 & 10876.76 & 1242.83 & 75133.82 \\
\hline Price-setting trades & 0.202 & 0.000 & 0.514 & 0.327 & 0.000 & 0.643 \\
\hline \multicolumn{7}{|c|}{ Traders with Profitable Mornings $(N=55,877)$ Normalized by Trader } \\
\hline Profits & 0.467 & 0.276 & 0.574 & 0.095 & 0.067 & 0.733 \\
\hline Number of trades & -0.035 & -0.159 & 0.986 & -0.066 & -0.234 & 0.980 \\
\hline Average trade size & -0.063 & -0.222 & 0.967 & -0.046 & -0.213 & 0.989 \\
\hline Total dollar risk & -0.122 & -0.317 & 0.776 & -0.100 & -0.335 & 0.801 \\
\hline Price-setting trades & -0.009 & -0.188 & 0.601 & -0.017 & -0.128 & 0.467 \\
\hline \multicolumn{7}{|c|}{ Traders with Losing Mornings $(N=26,718)$ Normalized by Trader } \\
\hline Profits & -0.563 & -0.273 & 0.727 & 0.082 & 0.067 & 0.915 \\
\hline Number of trades & 0.066 & -0.065 & 1.013 & 0.124 & -0.036 & 1.016 \\
\hline Average trade size & 0.119 & -0.081 & 1.040 & 0.086 & -0.114 & 1.006 \\
\hline Total dollar risk & 0.180 & -0.146 & 0.993 & 0.141 & -0.205 & 0.997 \\
\hline Price-setting trades & 0.018 & -0.171 & 0.619 & 0.036 & -0.116 & 0.526 \\
\hline
\end{tabular}

Panel B: Statistics by Day

\begin{tabular}{lrrrr}
\hline Variable & Mean & St. Dev. & Minimum & Maximum \\
\hline Afternoon price changes & 621.8703 & 215.383 & 195.00 & 1582.00 \\
Fraction with morning losses & 0.3238 & 0.049 & 0.20 & 0.50 \\
Fraction of loss-averse traders with losses & 0.3305 & 0.055 & 0.19 & 0.50 \\
Fraction of price-setting traders with losses & 0.3230 & 0.051 & 0.19 & 0.49 \\
\hline
\end{tabular}

In Table I, we report the mean, median, and standard deviation of morning and afternoon measures of profits, total number of trades, average trade size, total dollar risk, and number of price-setting trades (i.e., market orders). In the top third of Panel A, the statistics are calculated using raw data across all traders. The middle and bottom thirds of Panel A report statistics for traders having experienced profitable and losing mornings, respectively. The statistics reported in the middle and bottom thirds are calculated using the normalized measures of profits and risk-taking described above, which are used in most 
of our subsequent tests. ${ }^{15}$ Panel B of Table I reports several market summary statistics, including the number of afternoon price changes, the fraction of market participants with morning losses on a given day, the average trader's normalized morning profits on a given day, and a daily fraction of traders with morning profits, weighted by a trader-specific loss aversion coefficient described in Section IV.C.

Several points emerge from Table I that are worth noting. First, our panel of local trading days contains 82,595 observations. On the average (median) trader-day, around $\$ 2,500(\$ 1,000)$ in profits is earned, $190(140)$ trades are placed, with a size of around $10(4.5)$ lots each, and $\$ 20,000(\$ 2,400)$ of risk (standard deviation in total trader wealth) is assumed. Clearly, the averages are dominated by a small number of traders that trade in larger quantities, assume significantly more risk, and earn larger profits.

Turning to the bottom two-thirds of Panel A, we see that in $67 \%$ of the local trading days $(55,877)$, the given local traded profitably during the morning. As we see, on the average trader-morning, the winning trader's profit is 0.467 standard deviations above zero. For losing traders, on the average trader-morning they are 0.563 standard deviations below zero. These statistics are confirmed by those in Panel B, which reports that on the average day, the average trader's profit is 0.135 standard deviations above 0 and $32.4 \%$ of the pit has experienced losses. Next, we turn to our three measures of risk. Our hypotheses outlined in Section I all make predictions regarding the relationship between morning profits and afternoon risk-taking. When we take averages of observations associated with profitable and losing mornings, notice that the afternoon risk measures are far higher following losing mornings than following profitable mornings. Traders with losing mornings place far more trades $(0.124$ standard deviations above their daily average versus -0.066 ), place trades with larger average size ( 0.086 versus -0.046$)$, and assume greater total dollar risk $(0.141$ versus -0.100$)$ than those with profitable mornings. Moreover, the number of afternoon price-setting trades is also significantly larger for traders with morning losses, suggesting that losing traders are actively seeking out additional afternoon risk. This preliminary evidence suggests that traders exhibit behavior consistent with the loss aversion hypothesis. They assume greater risk following losing mornings and assume lower risk following profitable mornings.

However, we can also see from Table I that traders with losing mornings are not otherwise equivalent to traders with profitable mornings. They enter the afternoon having assumed far greater morning risk. Traders with losing mornings have placed $6.6 \%$ of one standard deviation more trades during the morning than average. They have traded in size that is $11.9 \%$ of a standard deviation above their average morning size. And they have assumed $18 \%$ of a

\footnotetext{
${ }^{15}$ Because traders place relatively few price-setting trades per day, they are only demeaned by traders in the middle and bottom third of Panel A.
} 
standard deviation more morning risk than usual. Thus, it is quite important that we control for these factors in a regression setting. ${ }^{16}$

Looking at afternoon returns, we see that they are only slightly lower following losing mornings than following profitable mornings (0.095 versus 0.082$)$. This suggests that the additional afternoon risk traders assume following losing mornings is not costly from an expected return standpoint. However, since traders with losing morning take more risk than other traders, afternoon returns are considerably lower for losing traders in risk-adjusted terms or as a fraction of the number of trades they place. Moreover, to the extent that traders seek to increase the spread in their afternoon returns following morning losses (e.g., due to loss aversion), we see that they are successful in achieving this objective, as the standard deviation of their overall afternoon return is notably larger following losing mornings than following winning mornings ( 0.915 versus 0.733 ). Now we turn to the regression setting to see whether these results are significant and robust to controlling for other factors.

\section{B. Morning Losses Lead to Afternoon Risk-Taking}

In Table II, we present results of regressions of afternoon risk-taking on morning profits. Included in the regressions are the absolute values of each trader's outstanding morning (11:00 a.m.) inventory, demeaned, and normalized by each trader's standard deviation of outstanding morning inventory. We include normalized inventory for three reasons. First, as noted above, traders with losing mornings tend to have larger outstanding positions heading into the afternoon, and we would like to control for the additional afternoon risk introduced by this position. Second, if traders do not begin each day with zero inventory, including each trader's absolute inventory may attenuate the bias that results in our measurement of profit and risk. Finally, in order to account for the possibility that traders unwind losing and winning positions in different ways, ${ }^{17}$ we include a term interacting morning profits and morning inventory. Specifically, our regression takes the following form:

$$
\operatorname{RISK}_{i, t}^{\mathrm{A}}=\alpha+\beta_{\pi} \pi_{i, t}^{\mathrm{M}}+\beta_{I}\left|\mathrm{INV}_{i, t}^{\mathrm{M}}\right|+\beta_{\pi I} \pi_{i, t}^{\mathrm{M}} \cdot\left|\mathrm{INV}_{i, t}^{\mathrm{M}}\right|+\beta_{R} \mathrm{RISK}_{i, t}^{\mathrm{M}}+\varepsilon_{i, t},
$$

where $\operatorname{RISK}_{i, t}^{\mathrm{A}}$ is one of the three normalized afternoon measures of risk for trader $i$ on date $t, \pi_{i, t}^{\mathrm{M}}$ is trader $i$ 's date $t$ morning profit, $\left|\mathrm{INV}_{i, t}^{\mathrm{M}}\right|$ is the absolute value of trader $i$ 's outstanding position (measured in thousands of contracts) at the end of the morning on date $t, \mathrm{RISK}_{i, t}^{\mathrm{M}}$ is trader $i$ 's morning risk measure on date $t$, and $\varepsilon_{i, t}$ is the error term.

We estimate our regressions in a variety of ways. First, we estimate a simple pooled-OLS regression. We also conduct regressions in the style of Fama and

\footnotetext{
${ }^{16}$ Of course, it is possible that the morning measures of risk are large for traders with morning losses because they have already become risk-seeking. Consistent with this, the regression results that follow are far stronger when the morning risk and other controls are omitted.

${ }^{17}$ This possibility is suggested by the findings of Shefrin and Statman (1985), Odean (1998a), and Locke and Mann (1999).
} 


\section{Table II}

\section{Morning Profits and Afternoon Risk-Taking}

This table reports the results of a number of different regressions relating morning profits to afternoon risk-taking by locals at the CBOT. All regressions have the basic form,

$$
\operatorname{RISK}_{i, t}^{\mathrm{A}}=\alpha+\beta_{\pi} \pi_{i, t}^{\mathrm{M}}+\beta_{I}\left|\mathrm{INV}_{i, t}^{\mathrm{M}}\right|+\beta_{\pi I} \pi_{i, t}^{\mathrm{M}} \cdot\left|\mathrm{INV}_{i, t}^{\mathrm{M}}\right|+\beta_{R} \mathrm{RISK}_{i, t}^{\mathrm{M}}+\varepsilon_{i, t} .
$$

The $t$-statistics are in parentheses. Risk is measured in three different ways, as the number of afternoon trades, the average size of afternoon trades, or the cumulative risk-weighted inventory of each trader. All variables that depend on measures of inventory are Winsorized at the 1 and $99 \%$ levels. The standard errors of the fixed-effects PCSE results are allowed to be heteroskedastic and concurrently correlated across locals. In Panel D, only the top (i.e., most profitable) $X \%$ of all traders on a given day are included in the regression, where $X$ is the fraction of traders with losses on that day. In Panels $\mathrm{A}-\mathrm{C}$, the sample contains 82,595 local-days. In Panel D the sample contains 65,061 local-days.

\begin{tabular}{|c|c|c|c|c|c|}
\hline Method & $\alpha$ & $\beta_{\pi}$ & $\beta_{I}$ & $\beta_{\pi I}$ & $\beta_{R}$ \\
\hline \multicolumn{6}{|c|}{ Panel A: Dependent Variable: Afternoon Number of Trades } \\
\hline \multirow[t]{2}{*}{ Pooled OLS } & 0.0187 & -0.1349 & 0.0313 & 0.056 & 0.2361 \\
\hline & $(4.88)$ & $(-23.38)$ & $(7.26)$ & (12.99) & $(61.66)$ \\
\hline \multirow[t]{2}{*}{ FM by trader } & 0.0315 & -0.1173 & 0.0511 & 0.058 & 0.2182 \\
\hline & $(2.35)$ & $(-4.62)$ & $(2.35)$ & $(7.49)$ & $(25.7)$ \\
\hline \multirow[t]{2}{*}{ FM by date } & -0.0143 & -0.1874 & 0.0378 & 0.0588 & 0.1499 \\
\hline & $(-0.49)$ & $(-27.89)$ & $(7.27)$ & $(10.33)$ & $(23.3)$ \\
\hline \multirow[t]{2}{*}{ Fixed effects PCSE } & - & -0.1362 & 0.03395 & 0.0547 & 0.2106 \\
\hline & - & $(-17.90)$ & $(5.44)$ & (11.36) & (12.07) \\
\hline
\end{tabular}

\begin{tabular}{|c|c|c|c|c|c|}
\hline \multicolumn{6}{|c|}{ Panel B: Dependent Variable: Afternoon Average Trade Size } \\
\hline \multirow{2}{*}{ Pooled OLS } & 0.0098 & -0.0691 & 0.0606 & 0.0203 & 0.2159 \\
\hline & $(2.53)$ & $(-11.95)$ & $(13.67)$ & $(4.69)$ & $(54.89)$ \\
\hline \multirow[t]{2}{*}{ FM by trader } & -0.0045 & -0.1013 & 0.0421 & 0.0227 & 0.2056 \\
\hline & $(-0.27)$ & $(-3.44)$ & $(1.41)$ & $(2.75)$ & $(23.79)$ \\
\hline \multirow[t]{2}{*}{ FM by date } & 0.0095 & -0.1076 & 0.0582 & 0.0290 & 0.1726 \\
\hline & $(0.65)$ & $(-11.86)$ & $(9.31)$ & $(3.83)$ & $(27.58)$ \\
\hline \multirow{2}{*}{ Fixed effects PCSE } & - & -0.7061 & 0.0594 & 0.0189 & 0.1964 \\
\hline & - & $(-11.16)$ & $(11.70)$ & $(4.18)$ & $(31.28)$ \\
\hline \multicolumn{6}{|c|}{ Panel C: Dependent Variable: Afternoon Total Dollar Risk } \\
\hline \multirow[t]{2}{*}{ Pooled OLS } & 0.0000 & -0.0079 & 0.5802 & 0.0134 & 0.3001 \\
\hline & $(0.02)$ & $(-3.00)$ & $(195.70)$ & $(6.80)$ & $(98.2)$ \\
\hline \multirow[t]{2}{*}{ FM by trader } & 0.0015 & -0.0107 & 0.6208 & 0.0170 & 0.2555 \\
\hline & $(1.55)$ & $(-2.41)$ & $(60.93)$ & $(4.27)$ & $(29.81)$ \\
\hline \multirow[t]{2}{*}{ FM by date } & -0.0007 & -0.0161 & 0.5812 & 0.0235 & 0.2868 \\
\hline & $(-0.12)$ & $(-3.91)$ & $(63.97)$ & $(4.75)$ & $(39.98)$ \\
\hline \multirow[t]{2}{*}{ Fixed effects PCSE } & - & -0.0091 & 0.5794 & 0.0139 & 0.2990 \\
\hline & - & $(-2.77)$ & (157.09) & $(6.34)$ & $(70.17)$ \\
\hline
\end{tabular}

\begin{tabular}{lccccc}
\hline \multicolumn{5}{c}{ Panel D: Dependent Variable: Afternoon Total Dollar Risk Matched } \\
\multicolumn{5}{c}{ Percentiles of Winners and Losers } \\
\hline Pooled OLS & -0.0003 & -0.0078 & 0.5925 & 0.0139 & 0.2933 \\
FM by trader & $(-0.17)$ & $(-2.83)$ & $(181.63)$ & $(6.75)$ & $(87.31)$ \\
& -0.0001 & -0.0095 & 0.6342 & 0.017 & 0.2501 \\
FM by date & $(-0.1)$ & $(-2.1)$ & $(61.62)$ & $(4.31)$ & $(28.65)$ \\
& -0.0014 & -0.0151 & 0.593 & 0.0232 & 0.2811 \\
Fixed effects PCSE & $(-0.22)$ & $(-3.57)$ & $(65.03)$ & $(4.64)$ & $(38.8)$ \\
& - & -0.0085 & 0.5913 & 0.0143 & 0.2927 \\
& - & $(-2.58)$ & $(147.79)$ & $(6.38)$ & $(63.92)$ \\
\hline
\end{tabular}


MacBeth (1969) in which we conduct trader-by-trader regressions and average the coefficients across traders, and we conduct day-by-day regressions and average the coefficients across days. The Fama-MacBeth regressions serve two purposes. First, they check whether our results are driven by cross-sectional or time-series correlation in residuals. Also, they test whether our results are driven more by particular traders or by particular days. We also conduct the panel regression with fixed effects for both traders and days and panel-corrected standard errors. ${ }^{18}$ In Panel A, we report the results of these regressions with the number of afternoon trades as the measure of afternoon risk-taking. Panel $B$ reports results of regressions using average trade size as the dependent variable. Finally, in Panel C, we document the results using total dollar risk.

As we can see, consistent with the results presented in Table I, our regressions indicate that traders are significantly loss averse. The results are highly significant across most of the different specifications. The regressions indicate that a one standard deviation decrease in morning profits leads the average trader to place $12-18 \%$ of one standard deviation more afternoon trades than normal (Panel A), place afternoon trades that are $7-11 \%$ of one standard deviation larger than normal (Panel B), and assume total dollar risk which is up to $1.6 \%$ of a standard deviation larger than normal (Panel C). The economic significance of morning profits in explaining afternoon total dollar risk (Panel C) is lower than that using other risk measures. The regressions using average afternoon trade size (Panel B) include somewhat fewer observations than the others because they only include traders who place at least one afternoon trade. The fact that traders with profitable mornings place afternoon trades that are of smaller size than average suggests the results are not entirely driven by a "framing effect" similar to the taxicab findings of Camerer et al. (1997). Traders with profitable mornings are not only more likely to stop trading in the afternoon-those that remain tend to trade less aggressively (in lower sizes) than normal.

As expected, the inventory terms are highly significant, indicating that traders with large midday positions assume additional afternoon risk as they unwind them (or that losing traders are already expanding their positions in order to assume greater afternoon risk). The morning risk variables are highly significant as well, indicating that traders who assume significant morning risk tend to continue to do so in the afternoon. To make sure our results are not driven by outliers or by the behavior of traders facing margin constraints, we rerun our regressions on the subset of traders whose morning profits did not deviate from zero by more than two standard deviations. Under this specification, which we do not report due to space considerations, the results are considerably stronger in economic and statistical terms.

A potential concern about our results is that we are measuring losses relative to zero, not relative to cross-sectional averages. One possibility for how this might influence the results is as follows. Suppose there is one set of traders

\footnotetext{
${ }^{18}$ Our panel-corrected standard error estimates adjust for contemporaneous correlation and heteroskedasticity across traders.
} 
that earn modest profits and assume modest morning and afternoon risk and there is another set that assumes a large amount of risk in mornings and afternoons and frequently incurs morning losses. In this case, traders with morning losses, who are mostly the high-risk traders, take more afternoon risk than the average trader, since the average trader's afternoon risk is determined partially by the low-risk traders. To make sure such an effect is not driving our results, we compare the afternoon risk-taking of traders with morning losses to the symmetric group of winners, rather than to all winners. That is, the fraction of traders that incur morning losses on a given day is compared to the equivalent fraction of largest winners. For example, if on a given day one-third of the traders have morning losses, their afternoon risk-taking is compared to the one-third of the sample that recorded the highest gains that morning. The results of regressions conducted on the data when it is parsed in this way, and using afternoon total dollar risk as the dependent variable, are reported in Panel D. As we can see, the results are highly consistent with those in Panel C. The point estimates are very close to those in Panel $\mathrm{C}$ and the coefficients on morning profits are significant across all four regression specifications.

One strong assumption in our above regressions is that morning risk-taking and midday inventory relate to afternoon risk-taking in a linear manner. Considering the strength of the coefficients on both controls, it may be worth examining the robustness of the results to the linearity assumption. To do so, we sort traders on each day into quintiles according to their morning profits and then, within each quintile, we sort them into quintiles according to morning risk-taking or morning inventory. Within each of the 25 resulting cells, we calculate the average afternoon risk-taking across all trader-days. The results when morning profits are sorted against our three measures of morning risktaking are reported in Table III. The results using morning inventory instead of morning risk-taking are highly similar and therefore are suppressed for brevity.

As Table III demonstrates, the results are highly robust to relaxing the linear specification. Within each quintile of morning risk-taking, afternoon risktaking is monotonically decreasing in the level of morning profits. Regardless of how or at what level morning risk-taking is measured, traders with low morning profits assume significantly larger afternoon risk than those with high morning profits. $^{19}$

As a final robustness check of our results, in Table IV we conduct logit regressions to see whether a trader's likelihood of assuming greater-than-average afternoon risk depends on whether the trader incurred morning losses. Specifically, we estimate the logit model defined by

$$
\operatorname{Prob}\left(\operatorname{RISK}_{i, t}^{\mathrm{A}}>0\right)=\frac{\exp X^{\prime} \beta}{1+\exp X^{\prime} \beta}
$$

\footnotetext{
${ }^{19}$ The only exception is in the bottom corner of Panel C, where for the highest morning profit and morning total dollar risk quintiles, we see an upturn in the level of afternoon risk-taking. Since no such pattern is found in either of the other two measures of risk-taking, we view this to be due to errors in the inventory measure that accumulate across the trading day (as discussed earlier).
} 


\section{Table III}

\section{Morning Profits and Afternoon Risk-Taking: Double Sorts}

This table reports the average afternoon risk-taking by locals at the CBOT when traders are sorted on each day into bins according to morning profits and morning risk-taking, and where morning risk-taking is measured as the number of trades, average trade size, and total dollar risk. Traders are sorted into quintiles according to morning profits and then, within each quintile, are sorted into quintiles according to morning risk-taking. Afternoon risk-taking measures are then averaged across traders in each cell. Standard errors are in parentheses. All variables that depend on measures of inventory are Winsorized at the 1 and 99\% levels. The sample contains 82,595 local-days.

\begin{tabular}{|c|c|c|c|c|c|}
\hline \multicolumn{6}{|c|}{ Panel A: Afternoon Number of Trades } \\
\hline \multirow[b]{2}{*}{ Morning Profits } & \multicolumn{5}{|c|}{ Morning Number of Trades } \\
\hline & 1 (low) & 2 & 3 & 4 & 5 (high) \\
\hline 1 (low) & $\begin{array}{c}-0.0498 \\
(0.0226)\end{array}$ & $\begin{array}{c}0.0359 \\
(0.0199)\end{array}$ & $\begin{array}{c}0.1385 \\
(0.0185)\end{array}$ & $\begin{array}{c}0.1679 \\
(0.0188)\end{array}$ & $\begin{array}{c}0.4264 \\
(0.0197)\end{array}$ \\
\hline 2 & $\begin{array}{c}-0.0639 \\
(0.0157)\end{array}$ & $\begin{array}{c}-0.0218 \\
(0.0182)\end{array}$ & $\begin{array}{c}0.0169 \\
(0.0191)\end{array}$ & $\begin{array}{c}0.145 \\
(0.0214)\end{array}$ & $\begin{array}{c}0.2965 \\
(0.024)\end{array}$ \\
\hline 3 & $\begin{array}{r}-0.1539 \\
(0.0159)\end{array}$ & $\begin{array}{c}-0.0899 \\
(0.0172)\end{array}$ & $\begin{array}{c}-0.0088 \\
(0.019)\end{array}$ & $\begin{array}{c}0.0288 \\
(0.0206)\end{array}$ & $\begin{array}{c}0.2229 \\
(0.0244)\end{array}$ \\
\hline 4 & $\begin{array}{c}-0.2404 \\
(0.0182)\end{array}$ & $\begin{array}{c}-0.1891 \\
(0.017)\end{array}$ & $\begin{array}{c}-0.0818 \\
(0.0181)\end{array}$ & $\begin{array}{c}-0.0283 \\
(0.0186)\end{array}$ & $\begin{array}{c}0.0852 \\
(0.021)\end{array}$ \\
\hline \multirow[t]{3}{*}{5 (high) } & $\begin{array}{c}-0.2983 \\
(0.0227)\end{array}$ & $\begin{array}{r}-0.2088 \\
(0.0189)\end{array}$ & $\begin{array}{c}-0.1626 \\
(0.0184)\end{array}$ & $\begin{array}{r}-0.0597 \\
(0.018)\end{array}$ & $\begin{array}{c}0.0578 \\
(0.0184)\end{array}$ \\
\hline & \multicolumn{4}{|c|}{ Panel B: Afternoon Average Trade Size } & \\
\hline & \multicolumn{5}{|c|}{ Morning Average Trade Size } \\
\hline Morning Profits & 1 (low) & 2 & 3 & 4 & 5 (high) \\
\hline 1 (low) & $\begin{array}{c}-0.225 \\
(0.0234)\end{array}$ & $\begin{array}{r}-0.0595 \\
(0.0204)\end{array}$ & $\begin{array}{c}0.0865 \\
(0.0192)\end{array}$ & $\begin{array}{c}0.2087 \\
(0.0184)\end{array}$ & $\begin{array}{c}0.4167 \\
(0.0188)\end{array}$ \\
\hline 2 & $\begin{array}{r}-0.1819 \\
(0.0162)\end{array}$ & $\begin{array}{c}-0.1271 \\
(0.0148)\end{array}$ & $\begin{array}{c}-0.0042 \\
(0.0163)\end{array}$ & $\begin{array}{l}0.094 \\
(0.0205)\end{array}$ & $\begin{array}{c}0.2725 \\
(0.0244)\end{array}$ \\
\hline 3 & $\begin{array}{r}-0.1761 \\
(0.0157)\end{array}$ & $\begin{array}{c}-0.1192 \\
(0.0168)\end{array}$ & $\begin{array}{c}-0.0239 \\
(0.0163)\end{array}$ & $\begin{array}{c}0.0695 \\
(0.0213)\end{array}$ & $\begin{array}{c}0.1796 \\
(0.0261)\end{array}$ \\
\hline 4 & $\begin{array}{r}-0.2288 \\
(0.0174)\end{array}$ & $\begin{array}{c}-0.1555 \\
(0.0172)\end{array}$ & $\begin{array}{c}-0.0491 \\
(0.019)\end{array}$ & $\begin{array}{c}0.0234 \\
(0.0183)\end{array}$ & $\begin{array}{c}0.1799 \\
(0.0232)\end{array}$ \\
\hline \multirow[t]{3}{*}{5 (high) } & $\begin{array}{c}-0.2905 \\
(0.0222)\end{array}$ & $\begin{array}{r}-0.2054 \\
(0.0191)\end{array}$ & $\begin{array}{c}-0.075 \\
(0.0184)\end{array}$ & $\begin{array}{c}0.0471 \\
(0.0183)\end{array}$ & $\begin{array}{c}0.1915 \\
(0.0207)\end{array}$ \\
\hline & \multicolumn{4}{|c|}{ Panel C: Afternoon Total Dollar Risk } & \\
\hline & \multicolumn{5}{|c|}{ Morning Total Dollar Risk } \\
\hline Morning Profits & 1 (low) & 2 & 3 & 4 & 5 (high) \\
\hline 1 (low) & $\begin{array}{c}-0.3069 \\
(0.0163)\end{array}$ & $\begin{array}{c}-0.2571 \\
(0.0075)\end{array}$ & $\begin{array}{c}-0.1572 \\
(0.0065)\end{array}$ & $\begin{array}{l}0.054 \\
(0.0068)\end{array}$ & $\begin{array}{c}1.0201 \\
(0.0081)\end{array}$ \\
\hline 2 & $\begin{array}{r}-0.4177 \\
(0.0125)\end{array}$ & $\begin{array}{l}-0.344 \\
(0.0061)\end{array}$ & $\begin{array}{c}-0.2171 \\
(0.0059)\end{array}$ & $\begin{array}{c}-0.0334 \\
(0.0064)\end{array}$ & $\begin{array}{c}0.5934 \\
(0.0091)\end{array}$ \\
\hline 3 & $\begin{array}{r}-0.4461 \\
(0.0112)\end{array}$ & $\begin{array}{c}-0.3432 \\
(0.0066)\end{array}$ & $\begin{array}{c}-0.2362 \\
(0.0064)\end{array}$ & $\begin{array}{c}-0.0559 \\
(0.0067)\end{array}$ & $\begin{array}{c}0.4879 \\
(0.0091)\end{array}$ \\
\hline 4 & $\begin{array}{c}-0.462 \\
(0.0102)\end{array}$ & $\begin{array}{c}-0.3522 \\
(0.0099)\end{array}$ & $\begin{array}{c}-0.2495 \\
(0.0099)\end{array}$ & $\begin{array}{l}-0.041 \\
(0.0104)\end{array}$ & $\begin{array}{c}0.5967 \\
(0.0114)\end{array}$ \\
\hline 5 (high) & $\begin{array}{r}-0.4879 \\
(0.0159)\end{array}$ & $\begin{array}{c}-0.3701 \\
(0.0274)\end{array}$ & $\begin{array}{c}-0.257 \\
(0.0276)\end{array}$ & $\begin{array}{c}0.0038 \\
(0.0255)\end{array}$ & $\begin{array}{c}1.1277 \\
(0.0191)\end{array}$ \\
\hline
\end{tabular}




\section{Table IV}

\section{Binary Results for Morning Profits and Afternoon Risk-Taking}

This table reports the results of a number of different logit models relating morning profits to afternoon risk-taking by locals at the CBOT. All models measure both morning profits and afternoon risk in a binary form, and the logit models have the basic form,

where

$$
\operatorname{Prob}\left(\mathrm{RISK}_{i, t}^{\mathrm{A}}>0\right)=\frac{\exp X^{\prime} \beta}{1+\exp X^{\prime} \beta},
$$

$$
X^{\prime} \beta=\alpha-\beta_{\pi} I\left(\pi_{i, t}^{\mathrm{M}}<0\right)+\beta_{I}\left|\operatorname{INV}_{i, t}^{\mathrm{M}}\right|+\beta_{\pi I} I\left(\pi_{i, t}^{\mathrm{M}}<0\right) \cdot\left|\mathrm{INV}_{i, t}^{\mathrm{M}}\right|+\beta_{R} \mathrm{RISK}_{i, t}^{\mathrm{M}} .
$$

The $t$-statistics are in parentheses. All variables that depend on measures of inventory are Winsorized at the 1 and $99 \%$ levels. In Panel D, only the top (i.e., most profitable) $X \%$ of all traders on a given day is included in the regression, where $X$ is the fraction of traders with losses on that day. In Panels A through C, the sample contains 82,595 local-days. In Panel D the sample contains 65,061 local-days.

\begin{tabular}{|c|c|c|c|c|c|}
\hline \multicolumn{6}{|c|}{ Panel B: Prob(Afternoon Average Trade Size > Mean Size) } \\
\hline Pooled logit & $\begin{array}{r}0.4581 \\
(2015.13)\end{array}$ & $\begin{array}{l}-0.1528 \\
(-78.94)\end{array}$ & $\begin{array}{l}-0.1083 \\
(-71.54)\end{array}$ & $\begin{array}{l}0.0118 \\
(0.51)\end{array}$ & $\begin{array}{r}-0.4223 \\
(-2070.04)\end{array}$ \\
\hline FM by trader & $\begin{array}{l}0.6396 \\
(4.39)\end{array}$ & $\begin{array}{l}-0.3140 \\
(-2.07)\end{array}$ & $\begin{array}{l}0.1272 \\
(0.60)\end{array}$ & $\begin{array}{l}-0.2697 \\
(-1.27)\end{array}$ & $\begin{array}{c}-0.488 \\
(-15.99)\end{array}$ \\
\hline FM by date & $\begin{array}{c}0.5192 \\
(15.59)\end{array}$ & $\begin{array}{l}-0.2012 \\
(-8.8)\end{array}$ & $\begin{array}{l}-0.1183 \\
(-6.11)\end{array}$ & $\begin{array}{l}-0.0111 \\
(-0.39)\end{array}$ & $\begin{array}{l}-0.3615 \\
(-26.17)\end{array}$ \\
\hline \multicolumn{6}{|c|}{ Panel C: Prob(Afternoon Total Dollar Risk > Mean Risk) } \\
\hline Pooled logit & $\begin{array}{l}-0.9595 \\
(-70.18)\end{array}$ & $\begin{array}{l}0.2032 \\
(9.34)\end{array}$ & $\begin{array}{l}2.0773 \\
(67.1)\end{array}$ & $\begin{array}{l}-0.5024 \\
(-11.6)\end{array}$ & $\begin{array}{l}1.4089 \\
(60.03)\end{array}$ \\
\hline FM by trader & $\begin{array}{l}-0.7171 \\
(-18.74)\end{array}$ & $\begin{array}{l}0.0572 \\
(0.97)\end{array}$ & $\begin{array}{l}4.4364 \\
(11.52)\end{array}$ & $\begin{array}{l}1.1028 \\
(1.35)\end{array}$ & $\begin{array}{l}1.6801 \\
(20.21)\end{array}$ \\
\hline FM by date & $\begin{array}{l}-0.9726 \\
(-31.06)\end{array}$ & $\begin{array}{c}0.191 \\
(6.57)\end{array}$ & $\begin{array}{c}2.516 \\
(30.94)\end{array}$ & $\begin{array}{l}-0.4388 \\
(-5.12)\end{array}$ & $\begin{array}{l}1.5145 \\
(36.12)\end{array}$ \\
\hline \multicolumn{6}{|c|}{$\begin{array}{c}\text { Panel D: Regressions Requiring Matched Percentiles of Winners and Losers } \\
\text { Prob(Afternoon Total Dollar Risk > Mean Risk) }\end{array}$} \\
\hline Pooled logit & $\begin{array}{l}-0.9001 \\
(-55.94)\end{array}$ & $\begin{array}{c}0.146 \\
(6.27)\end{array}$ & $\begin{array}{l}2.1477 \\
(59.45)\end{array}$ & $\begin{array}{l}-0.5587 \\
(-11.92)\end{array}$ & $\begin{array}{l}1.3616 \\
(54.82)\end{array}$ \\
\hline FM by trader & $\begin{array}{l}-0.7107 \\
(-11.00)\end{array}$ & $\begin{array}{l}0.056 \\
(0.70)\end{array}$ & $\begin{array}{l}6.1548 \\
(10.91)\end{array}$ & $\begin{array}{l}-0.7123 \\
(-0.80)\end{array}$ & $\begin{array}{l}1.7579 \\
(15.81)\end{array}$ \\
\hline FM by date & $\begin{array}{l}-0.9124 \\
(-26.96)\end{array}$ & $\begin{array}{l}0.1354 \\
(4.43)\end{array}$ & $\begin{array}{c}2.693 \\
(28.95)\end{array}$ & $\begin{array}{l}-0.6009 \\
(-6.02)\end{array}$ & $\begin{array}{l}1.4724 \\
(37.2)\end{array}$ \\
\hline
\end{tabular}

\begin{tabular}{lccccc}
\hline Method & $\alpha$ & $\beta_{\pi}$ & $\beta_{I}$ & $\beta_{\pi I}$ & $\beta_{R}$ \\
\hline & \multicolumn{2}{c}{ Panel A: Prob(Afternoon Number of Trades > Mean Trades) } & \\
\hline Pooled logit & 0.375 & -0.2875 & -0.0801 & 0.0537 & -0.3865 \\
& $(1384.93)$ & $(-286.97)$ & $(-41.82)$ & $(11.71)$ & $(-2107.91)$ \\
FM by trader & 0.2766 & -0.1989 & -0.3139 & 0.3088 & -0.4017 \\
& $(1.54)$ & $(-1.02)$ & $(-1.11)$ & $(1.11)$ & $(-14.87)$ \\
FM by date & 0.553 & -0.3466 & -0.0947 & 0.0844 & -0.331 \\
& $(8.58)$ & $(-11.45)$ & $(-4.48)$ & $(1.88)$ & $(-17.94)$
\end{tabular}


where

$X^{\prime} \beta=\alpha-\beta_{\pi} I\left(\pi_{i, t}^{\mathrm{M}}<0\right)+\beta_{I}\left|\mathrm{INV}_{i, t}^{\mathrm{M}}\right|+\beta_{\pi I} I\left(\pi_{i, t}^{\mathrm{M}}<0\right) \cdot\left|\mathrm{INV}_{i, t}^{\mathrm{M}}\right|+\beta_{R} \mathrm{RISK}_{i, t}^{\mathrm{M}}$,

and where $I\left(\pi_{i, t}^{\mathrm{M}}<0\right)$ is an indicator variable that is equal to one if trader $i$ 's morning profit on date $t$ is negative. Note that the term $-\beta_{\pi} I\left(\pi_{i, t}^{\mathrm{M}}<0\right)$ enters the regression equation with a negative sign in order to make the expected sign of the coefficients negative under loss aversion.

Again, the morning losses enter significantly in almost all regressions. The fact that the Fama-MacBeth regression by date yields consistently stronger estimates than the regression by trader (as was the case in Table II) implies that our results are driven more by the profits/risk-taking relation across traders on particular days than by the relation across days for particular traders. Our binary results also offer an alternate estimate of the economic significance of our results. Using the pooled logit regressions from Table III, and evaluating them with independent variables at their means, traders that lose money in the morning increase their probability of assuming above-average afternoon risk from 26.9 to $31.3 \%$. This represents an increase in likelihood of slightly more than $16 \%$. Overall, Tables II-IV make a strong case that market makers at the CBOT behave in a loss-averse manner.

\section{Semiparametric Regressions}

In their calibrations of loss-averse utility functions, Kahneman and Tversky (1979) estimate that individual utility functions have a kink at zero and convexity over losses that is roughly equal to their concavity over gains. To investigate whether the afternoon responses of traders with morning losses are symmetric to those with morning gains, we conduct a series of semiparametric regressions that permit a nonlinear relationship between morning returns and afternoon risk-taking. Specifically, we rank traders each day according to their normalized morning profit and assign them to one of 20 profitability groups. ${ }^{20}$ We then conduct daily cross-sectional regressions of the following form:

$$
\begin{aligned}
\operatorname{RISK}_{i, t}^{\mathrm{A}}= & \alpha+\sum_{j=1}^{20} \beta_{\pi, j} D_{i, j, t}+\beta_{I}\left|\mathrm{INV}_{i, t}^{\mathrm{M}}\right|+\sum_{j=1}^{20} \beta_{\pi I, j} D_{i, j, t} \cdot\left|\mathrm{INV}_{i, t}^{\mathrm{M}}\right| \\
& +\beta_{R} \mathrm{RISK}_{i, t}^{\mathrm{M}}+\varepsilon_{i, t},
\end{aligned}
$$

where $D_{i, j, t}$ is a dummy variable that is equal to one if trader $i$ 's morning profit ranks in group $j$ on date $t$. We then average the cross-sectional regression coefficients across time and calculate the corresponding standard errors. Figure 1 plots the average of the morning profit regression coefficients for each of the 20 profit percentile groups when total afternoon dollar risk is used as the

\footnotetext{
${ }^{20}$ To ensure that the zero-profit level does not move around across the year, we create the profitability bins using the entire year of morning profit observations.
} 
Standardized

Afternoon

Risk - Taking

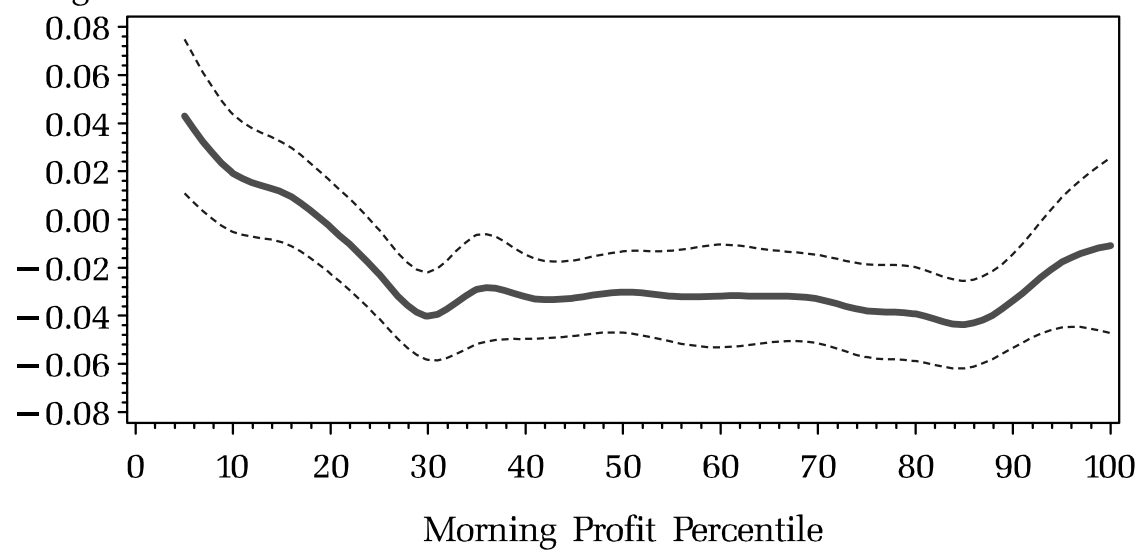

Figure 1. Morning profit percentile and afternoon risk-taking. This figure plots the timeseries averages of 236 daily cross-sectional semiparametric regressions of afternoon total dollar risk on morning profit percentile. The regressions are kernel-smoothed and the dashed lines reflect two standard error bands of the time series-averaged regressions.

dependent variable. A kernel-smoothed line is plotted across these coefficients and two standard error bands are included to reflect significance.

The figure highlights a significant asymmetry between the responses of traders with profitable mornings and those with losing mornings. Consistent with the above results, traders with losing mornings increase their afternoon risk-taking significantly. Moreover, the smaller the morning losses, the smaller the increase in afternoon risk-taking. The relationship holds up until around the $30^{\text {th }}$ percentile of morning profitability. Given that this is the point in the ranking where the traders earn zero profits, it is highly consistent with the findings of Kahneman and Tversky (1979), who estimate that utility functions shift at zero from convex to concave with a kink.

As we move into the positive range of trader morning profitability, the picture changes. Traders with profitable mornings all take on relatively similar, belowaverage, levels of afternoon risk. Only traders who experience extremely high profits differ at all in their afternoon risk-taking. Traders in the final few percentiles exhibit a slight increase in their afternoon risk-taking. This increase could be consistent with a house-money effect; however, the increase is not statistically significant, and is economically much smaller than the increased risk-taking of traders with losing mornings. Moreover, this increase does not appear in the double sorts of trade size or number of trades in Table III. Thus, it appears that the relation between morning profitability and afternoon risktaking is not symmetric, with losing trader behavior being more sensitive to the level of their losses than winning traders to the level of their gains. 


\section{Time until Midday Position Unwound}

The findings of Shefrin and Statman (1985), Odean (1998a), and Locke and Mann (1999) all suggest that traders may be subject to the disposition effect. That is, they may be more reluctant to unwind losing positions than winning positions. Our results thus far indicate that traders who lose money in the mornings assume greater afternoon risk. To investigate the extent to which this is driven by trader reluctance to unwind losing midday positions, we employ a hazard model to estimate the time traders take to unwind their midday inventory.

The hazard model we employ is the Cox proportional hazard model. In this model, the instantaneous probability of unwinding a position, conditional on not having unwound the position until now, is given by the hazard rate, which we model as

$$
\begin{aligned}
h(\tau, x)= & h_{0}(\tau)\left[\operatorname { e x p } \left\{\beta_{V} \operatorname{INV}_{i, t}^{\mathrm{M}}\left(P_{t}^{\mathrm{M}}-\bar{P}_{i, t}^{I}\right)+\beta_{\pi} \pi_{i, t}^{\mathrm{M}}\right.\right. \\
& \left.\left.+\beta_{I}\left|\mathrm{INV}_{i, t}^{\mathrm{M}}\right|+\beta_{R} \operatorname{RISK}_{i, t}^{\mathrm{M}}\right\}\right],
\end{aligned}
$$

where $h_{0}(\tau)$ is a baseline hazard function, $\tau$ measures the time since 11 a.m. on day $t, P_{t}^{\mathrm{M}}$ is the futures contract price at 11 a.m. on day $t, \bar{P}_{i, t}^{I}$ is the contractweighted average price at which trader $i$ acquired his inventory on day $t$, and the other variables are as defined above. We do not estimate the baseline hazard function, but we estimate the coefficients on the terms that shift the baseline hazard up and down for particular individuals. Since we are modeling the time required to reverse a position at midday, the baseline hazard function captures the unconditional probability of position reversal at each instant between 11:00 a.m. and market close at 2:00 p.m., including any effect of the time of day. Given the proportional hazard form, a positive coefficient on a particular variable increases the hazard for unwinding a position, shortening the time until unwinding the position as the explanatory variable increases. Thus, to be consistent with the disposition effect, we expect the value of the coefficient on value $\left(\beta_{V}\right)$ to be positive. The results are reported in Table V.

Beginning with the pooled regression results, we see that both position value and morning profits are highly significant in explaining the speed at which midday positions are unwound. Consistent with the disposition effect, traders that take a losing position into the afternoon tend to take longer to unwind it than those with a winning position. For example, a trader that has a 30 contract position that is under water by one tick will lower his hazard rate, on average, by $2.9 \%$. However, a trader's overall morning profits also help explain how long the trader takes to unwind his midday position. If the same trader enters the afternoon with overall morning profits that are one standard deviation below zero, he has a hazard rate that is an additional 3.3\% lower (for a total decrease of $6.2 \%$ ) than if he had no morning losses overall. Since a trader wishing to assume greater afternoon risk can either trade in larger quantities or hold existing positions longer, this result is perfectly consistent with the loss-averse behavior documented above. 


\section{Table V}

\section{Hazard Model for Time until Midday Position Unwound}

This table reports the results of a Cox proportional hazard model measuring the time it takes traders to unwind positions they have at 11:00 a.m. conditional on their morning profit or loss and the value of their position. Specifically, the hazard rate for reversing a given position is

$$
h(t, x)=h_{0}(t)\left[\exp \left\{\beta_{V} \mathrm{INV}_{i, t}^{\mathrm{M}}\left(P_{t}^{\mathrm{M}}-\bar{P}_{i, t}^{I}\right)+\beta_{\pi} \pi_{i, t}^{\mathrm{M}}+\beta_{I}\left|\operatorname{INV}_{i, t}^{\mathrm{M}}\right|+\beta_{R} \mathrm{RISK}_{i, t}^{\mathrm{M}}\right\}\right],
$$

where $h_{0}(t)$ is a baseline hazard function, $P_{t}^{\mathrm{M}}$ is the futures price at $11 \mathrm{a} . \mathrm{m}$. on day $t$, and $\bar{P}_{i, t}^{I}$ is the contract-weighted average price at which trader $i$ acquired his inventory on day $t$. The $t$-statistics are in parentheses. All variables (except time to unwind) are Winsorized at the 1 and $99 \%$ levels. The sample contains 82,595 local-days.

\begin{tabular}{lcccc}
\hline Method & $\beta_{V}$ & $\beta_{\pi}$ & $\beta_{I}$ & $\beta_{R}$ \\
\hline \multirow{4}{*}{ Pooled Cox model } & Dependent Variable: Time & until Midday Position Unwound & \\
& 0.0283 & 0.0321 & -0.0094 & -0.0158 \\
FM by trader & $(5.11)$ & $(5.49)$ & $(-1.82)$ & $(-1.13)$ \\
& 0.0187 & 0.0178 & -0.1067 & -0.4013 \\
FM by date & $(0.90)$ & $(1.11)$ & $(-1.50)$ & $(-1.44)$ \\
& 0.0312 & 0.0577 & -0.0042 & -0.0155 \\
& $(6.54)$ & $(4.83)$ & $(-0.37)$ & $(-1.36)$ \\
\hline
\end{tabular}

For robustness, we estimate the hazard model for each trader and then average the coefficients across traders. We estimate the hazard model on each day of our sample and then average the coefficients across days. Although the signs and magnitudes are all consistent with the pooled regression, the standard errors of our estimates become much larger when we average the coefficients across traders. Only when we estimate the model on each day and then average across days do the coefficients retain their statistical significance. In unreported robustness checks, we estimated a single-variable hazard model for each of the above explanatory variables. When inventory is the only explanatory variable, its sign is, as one would expect, positive and highly significant. When the value of the position is the only variable included, its coefficient estimate is unchanged from the multivariate model, suggesting that correlation between the value of the midday position and overall morning profits is not distorting our results.

\section{E. Profits and Risk-Taking across Days}

As we have argued, there are compelling institutional and behavioral factors that justify a 1-day horizon for our traders. However, it is possible that all traders do not exclusively evaluate their profits at the daily horizon and that other horizons are important. One of the important aspects of testing at a daily horizon in our setting is that because traders seldom enter the trading day with outstanding positions, our traders can attribute their performance during the morning entirely to trades executed that morning. Although this possibility 
disappears if we test at an hourly horizon, it does not if we move to the multiday setting-profits earned during a particular day can be attributed entirely to decisions made that day. Thus, to see whether our findings are exclusive to the 1-day horizon, or whether they are detectable at lower frequencies, we examine the relationship between profits and risk-taking across trading days.

To examine profits and risk-taking across days, we compare overlapping pairs of trader-days. Specifically, we ask whether profits on one day explain a trader's level of risk-taking the next. An attractive feature of the multiday setting is that unlike the morning-afternoon tests, we do not need to worry about a trader having an outstanding position following a losing day that influences our measurement of his risk-taking activity on the following day. Since we assume that traders hold no position overnight, inventory is always zero at the beginning of each day and traders must enter trades to incur risk. We estimate the regressions employed above without the inventory controls, simply regressing a trader's level of daily risk on his previous day's profit and previous day's risk. As in the earlier tests, we again normalize the profit and risk measures by traders, though we now use daily averages and standard deviations.

Daily regressions of risk-taking on profits corresponding to those presented in Tables II and IV were conducted. When we use continuous measures of risk and profits (as in Table II), no detectable relationship exists between profit and risk across trading days, whether we run pooled OLS, panel, or FamaMacBeth style regressions. Likewise, when we employ discrete measures of risk and profits (as in Table IV), the results are consistently insignificant. To conserve space, we do not report the results of these regressions. They suggest, however, that horizon effects can be quite important in identifying loss-averse behavior, and that for our set of traders, loss aversion is only pronounced at the daily horizon.

\section{Evidence for Price Impact}

Having documented strong evidence supporting the hypothesis of loss aversion among our traders, we now turn to the question of whether this loss aversion matters for prices. The second hypothesis that we examine relates each trader's performance in the morning to his probability of setting prices in the afternoon. In particular, we examine whether traders with morning losses tend to buy or sell when the price moves up or down. Our third hypothesis concerns the permanence of the prices set by traders with losses. We estimate the expected price 10 minutes after a price change, conditional on whether the trader that moved the prices had losses or gains in the morning. Our final hypothesis relates aggregate morning losses to afternoon volatility. We test whether mornings with widespread losses lead to more volatile afternoons.

\section{A. Morning Profits and Afternoon Price Leadership}

We begin by identifying trades placed by locals that move the price in a direction consistent with their trade. In a futures pit, traders do not post bid and 
ask prices as market makers do on an exchange floor. Rather, a group of traders stands ready to buy at a particular price, and a group stands ready to sell at a different, higher price. When large buy orders arrive from customers outside the pit, the orders generally are filled at the higher price. Large sales orders similarly go through at the lower price. The posted futures price therefore oscillates between the effective bid and ask price throughout the day. We identify trades that cause the posted price to change from bid to ask (or from ask to bid) because of the purchase or sale of a local trader for his own account. Specifically, we compare the price of a given local trade to the price of the previous trade. If the local purchases at a price that is higher than the previous price, we identify the trade as responsible for having raised the price. Likewise, if the local sells at a price that is lower than the previous price, we identify the trade as responsible for lowering the price. Although the actual bid and ask prices at a given point in time are not recorded by the CBOT, under conditions when they are well defined for market participants, price-setting trades resemble market orders. Locals do not execute price-setting trades very frequently. In order to be certain that an identified price move is caused by a local, we drop any trade that occurs during the same second as another trade. Across all locals and days, the average number of price-moving trades per afternoon is 0.327 per trader, for a total of around 140 price-moving trades executed by locals on a given afternoon.

Having identified trades that have moved the price, we then ask whether traders place more price-moving trades following losing mornings than following profitable mornings. Specifically, we regress the number of price-setting trades placed by a trader on a given afternoon (relative to his average) on the trader's morning returns and his morning inventory. Our regressions take the following form:

$$
\Delta_{i, t}^{\mathrm{A}}-\bar{\Delta}_{i}^{\mathrm{A}}=\alpha+\beta_{\pi} \pi_{i, t}^{\mathrm{M}}+\beta_{I}\left|\mathrm{INV}_{i, t}^{\mathrm{M}}\right|+\beta_{\pi I} \pi_{i, t}^{\mathrm{M}} \cdot\left|\mathrm{INV}_{i, t}^{\mathrm{M}}\right|+\varepsilon_{t}^{i},
$$

where $\Delta_{i, t}^{\mathrm{A}}$ is the number of price-setting trades placed in the afternoon of day $t$ by trader $i, \bar{\Delta}_{i}^{\mathrm{A}}$ is trader $i$ 's average number of price-setting trades per afternoon, and other variables are as defined earlier.

The results of pooled OLS, fixed effects, and Fama-MacBeth style crosssectional and time-series regressions are reported in Table VI. Panel A reports the results for all trades. Panels $\mathrm{B}$ and $\mathrm{C}$ report regression results in which price-setting trades are separated into those that are inventory-expanding and inventory-contracting, respectively. In all specifications, the results are highly significant. A trader who experiences a one standard deviation loss in the morning places between 0.047 and 0.061 more afternoon price-setting trades than he does on an average afternoon. Since traders only place 0.327 price-setting trades per afternoon, the results are economically significant. Experiencing a one standard deviation morning loss increases the average number of afternoon price-setting trades by between 20 and 25\%. In Panels B and C, we see that traders with morning losses are more likely to place price-setting trades in the afternoon to both reduce as well as expand their inventory. Consistent with the earlier results on average afternoon trade size, these results suggest that 


\section{Table VI}

\section{Morning Profits and Afternoon Price Leadership}

This table reports the results of a number of different regressions relating afternoon risk-taking to afternoon price leadership by locals at the CBOT. All regressions have the basic form,

$$
\Delta_{i, t}^{\mathrm{A}}-\bar{\Delta}_{i}^{\mathrm{A}}=\alpha+\beta_{\pi} \pi_{i, t}^{\mathrm{M}}+\beta_{I}\left|\mathrm{INV}_{i, t}^{\mathrm{M}}\right|+\beta_{\pi I} \pi_{i, t}^{\mathrm{M}} \cdot\left|\mathrm{INV}_{i, t}^{\mathrm{M}}\right|+\varepsilon_{i, t},
$$

where $\Delta_{i, t}^{\mathrm{A}}$ is the number of price-setting trades made by trader $i$ on the afternoon of date $t$. This is compared to its average level for trader $i, \bar{\Delta}_{i}^{\mathrm{A}}$, and then regressed on the explanatory variables used above. All variables that depend on measures of inventory are Winsorized at the 1 and $99 \%$ levels. The $t$-statistics are in parentheses. Regressions on an indicator variable that is equal to 1 when morning profits are positive result in qualitatively identical inferences, as do ordered logit regressions with fixed effects by trader.

\begin{tabular}{|c|c|c|c|c|}
\hline \multicolumn{5}{|c|}{ Dependent Variable: Afternoon Number of Price-Setting Trades $\left(\Delta_{i, t}^{\mathrm{A}}-\bar{\Delta}_{i}^{\mathrm{A}}\right)$} \\
\hline Method & $\alpha$ & $\beta_{\pi}$ & $\beta_{I}$ & $\beta_{\pi I}$ \\
\hline \multicolumn{5}{|c|}{ Panel A: All Trades } \\
\hline Pooled OLS & $\begin{array}{l}0.0014 \\
(0.81)\end{array}$ & $\begin{array}{c}-0.0493 \\
(-18.37)\end{array}$ & $\begin{array}{l}0.0057 \\
(2.89)\end{array}$ & $\begin{array}{c}-0.024 \\
(-12.88)\end{array}$ \\
\hline FM by trader & $\begin{array}{l}-0.0014 \\
(-1.05)\end{array}$ & $\begin{array}{l}-0.0474 \\
(-10.21)\end{array}$ & $\begin{array}{l}0.0076 \\
(2.74)\end{array}$ & $\begin{array}{l}-0.0203 \\
(-6.58)\end{array}$ \\
\hline FM by date & $\begin{array}{l}0.0493 \\
(3.58)\end{array}$ & $\begin{array}{c}-0.061 \\
(-15.45)\end{array}$ & $\begin{array}{l}0.0072 \\
(3.11)\end{array}$ & $\begin{array}{l}-0.0119 \\
(-4.19)\end{array}$ \\
\hline Fixed effects PCSE & $\begin{array}{l}- \\
-\end{array}$ & $\begin{array}{l}-0.0484 \\
(-15.87)\end{array}$ & $\begin{array}{l}0.0083 \\
(3.81)\end{array}$ & $\begin{array}{l}-0.0145 \\
(-6.95)\end{array}$ \\
\hline \multicolumn{5}{|c|}{ Panel B: Inventory Expanding Trades } \\
\hline Pooled OLS & $\begin{array}{l}0.0010 \\
(0.08)\end{array}$ & $\begin{array}{l}-0.0251 \\
(-13.80)\end{array}$ & $\begin{array}{l}0.0007 \\
(0.55)\end{array}$ & $\begin{array}{l}-0.0189 \\
(-14.50)\end{array}$ \\
\hline FM by trader & $\begin{array}{l}-0.0004 \\
(-0.54)\end{array}$ & $\begin{array}{l}-0.0239 \\
(-8.51)\end{array}$ & $\begin{array}{l}0.0026 \\
(1.27)\end{array}$ & $\begin{array}{c}-0.0176 \\
(8.01)\end{array}$ \\
\hline FM by date & $\begin{array}{l}0.0508 \\
(3.72)\end{array}$ & $\begin{array}{l}-0.0311 \\
(-11.65)\end{array}$ & $\begin{array}{l}0.0039 \\
(2.58)\end{array}$ & $\begin{array}{l}-0.0112 \\
(-4.98)\end{array}$ \\
\hline Fixed effects PCSE & $\begin{array}{l}- \\
-\end{array}$ & $\begin{array}{l}-0.0240 \\
(-12.05)\end{array}$ & $\begin{array}{l}0.0028 \\
(2.00)\end{array}$ & $\begin{array}{l}-0.0118 \\
(-8.41)\end{array}$ \\
\hline \multicolumn{5}{|c|}{ Panel C: Inventory Contracting Trades } \\
\hline Pooled OLS & $\begin{array}{l}0.0013 \\
(1.01)\end{array}$ & $\begin{array}{c}-0.0291 \\
(-15.69)\end{array}$ & $\begin{array}{l}0.0008 \\
(0.59)\end{array}$ & $\begin{array}{c}-0.018 \\
(-13.66)\end{array}$ \\
\hline FM by trader & $\begin{array}{l}-0.0008 \\
(-1.00)\end{array}$ & $\begin{array}{l}-0.0274 \\
(-9.53)\end{array}$ & $\begin{array}{l}0.0028 \\
(1.42)\end{array}$ & $\begin{array}{l}-0.0153 \\
(-6.82)\end{array}$ \\
\hline FM by date & $\begin{array}{l}0.0524 \\
(3.76)\end{array}$ & $\begin{array}{c}-0.0364 \\
(-13.46)\end{array}$ & $\begin{array}{l}0.0019 \\
(1.11)\end{array}$ & $\begin{array}{l}-0.0128 \\
(-5.51)\end{array}$ \\
\hline Fixed effects PCSE & $\begin{array}{l}- \\
-\end{array}$ & $\begin{array}{l}-0.0278 \\
(-13.69)\end{array}$ & $\begin{array}{l}0.0027 \\
(0.06)\end{array}$ & $\begin{array}{l}-0.0109 \\
(-7.72)\end{array}$ \\
\hline
\end{tabular}

traders who incur morning losses are not passively assuming more afternoon risk. To obtain the additional risk, they appear to be frequently hitting existing limit orders at prices that are less favorable than those of previous trades. This implies that traders with morning losses cannot easily assume the additional 
afternoon risk they desire and must give up an edge to obtain the additional exposure. Again, the results are highly significant across all the regression specifications, and appear strong both in the time series and in the cross-section. The results also obtain if binary specifications of morning profit and afternoon risk-taking replace the continuous variables used in Table VI, or if an ordered logit model with trader-specific fixed effects replaces the demeaned regression specification reported here.

While a subset of the afternoon trades of traders with losing mornings appears to move prices, if they are motivated by loss aversion, the price impact of such trades should be less permanent than that of trades that are information based. Moreover, given that these traders are likely to unwind their positions as the day progresses, we should expect the price impact of position-initiating trades to disappear as the day moves forward. We investigate these issues in the following section.

\section{B. Loss Aversion and Price Permanence}

The price-setting trades we identify in the previous section appear to be motivated by loss-averse traders eager to assume additional afternoon risk to improve their odds of recovering morning losses. If this is indeed the case, and the trades are not based on information about the fundamental value of the futures contract, we should expect them to have a more transitory impact on prices than trades based on information. Moreover, an examination of the quality of price-setting trades placed by loss-averse traders gives us a further idea about their afternoon trade performance in relation to their morning profitability. To pursue this, we compare the price permanence of price-setting trades placed by traders with morning losses to those placed by traders with morning profits. If afternoon trades placed by traders with profitable mornings are more likely to be informed trades than those placed by traders with losing mornings, we should expect the prices set by profitable traders to be far more permanent than those set by traders trying to recover their losses.

To examine the price permanence of our traders' price-setting trades, we divide the trades according to the price sequence leading up to the price-setting trade. Trades are grouped according to the sequence generated by the past four price ticks. Interpreting the tick-by-tick price rises and declines symmetrically, we denote a price change as a continuation $(C)$ if it is in the same direction as the previous price change and as a reversal $(R)$ if it is not. For example, the price sequence 25-24-25-26 would be denoted as $\mathrm{RC}$ since the second 25 results in a reversal (25-24-25) and the 26 is a continuation (24-25-26). Thus four past prices yield four distinct change categories: CC, CR, RC, and RR. Clearly, RR is the most common of the four possibilities (77\% of the price-setting trades) followed by CR (15\%), RC (7\%), and CC (1\%).

Price-setting trades are further divided according to whether they resulted in a contraction or an expansion of the trader's existing position and according to whether or not the trader experienced a loss in the morning. Reversals are then averaged within each category according to the fraction of the price-setting 


\section{Table VII \\ Price Reversals}

This table reports the average price reversals that follow the price-setting trades placed by the traders in our sample. Price reversals are measured as the fraction of the price-setting trade's price change that is reversed during the next 5 minutes. The price-setting trades are divided according to the price path sequence leading up to the trade. The first column identifies the price path sequence of the last four trades, with $\mathrm{C}$ denoting a continuation and $\mathrm{R}$ denoting a reversal. For example, if one of our traders places the final trade in the sequence 25-24-25-26, this would be included in the category RC. Price-setting trades are further divided according to whether the trade resulted in an expanded or contracted inventory for the trader and whether or not the trader experienced a morning loss. Differences between the price reversals that follow price-setting trades of traders with morning losses and those with no morning loss are recorded in columns 4 and 7 . The $t$-statistics are in parentheses.

\begin{tabular}{|c|c|c|c|c|c|c|}
\hline \multicolumn{7}{|c|}{ Five-Minute Price Changes in Ticks } \\
\hline \multirow[b]{2}{*}{ Price Path } & \multicolumn{3}{|c|}{ Contracting } & \multicolumn{3}{|c|}{ Expanding } \\
\hline & Loss & No Loss & Diff. & Loss & No Loss & Diff. \\
\hline $\mathrm{CC}$ & $\begin{array}{l}2.0000 \\
(3.3)\end{array}$ & $\begin{array}{l}2.0211 \\
(5.7)\end{array}$ & $\begin{array}{c}-0.0211 \\
(0.0)\end{array}$ & $\begin{array}{l}3.5411 \\
(4.4)\end{array}$ & $\begin{array}{l}1.5040 \\
(2.2)\end{array}$ & $\begin{array}{l}2.0371 \\
(1.9)\end{array}$ \\
\hline $\mathrm{RC}$ & $\begin{array}{l}2.0365 \\
(16.1)\end{array}$ & $\begin{array}{l}1.8333 \\
(21.0)\end{array}$ & $\begin{array}{l}0.2032 \\
(1.3)\end{array}$ & $\begin{array}{l}2.5165 \\
(15.5)\end{array}$ & $\begin{array}{l}1.9667 \\
(22.6)\end{array}$ & $\begin{array}{l}0.5498 \\
(3.0)\end{array}$ \\
\hline $\mathrm{CR}$ & $\begin{array}{l}0.8141 \\
(9.2)\end{array}$ & $\begin{array}{l}0.6806 \\
(10.4)\end{array}$ & $\begin{array}{l}0.1334 \\
(1.2)\end{array}$ & $\begin{array}{l}0.8211 \\
(7.0)\end{array}$ & $\begin{array}{l}0.6883 \\
(11.2)\end{array}$ & $\begin{array}{l}0.1328 \\
(1.0)\end{array}$ \\
\hline $\mathrm{RR}$ & $\begin{array}{l}0.6640 \\
(19.7)\end{array}$ & $\begin{array}{c}0.7350 \\
(27.2)\end{array}$ & $\begin{array}{l}-0.0710 \\
(-1.6)\end{array}$ & $\begin{array}{l}0.8461 \\
(20.3)\end{array}$ & $\begin{array}{l}0.6950 \\
(28.9)\end{array}$ & $\begin{array}{l}0.1510 \\
(3.1)\end{array}$ \\
\hline Average & $\begin{array}{l}0.8035 \\
(25.7)\end{array}$ & $\begin{array}{l}0.8166 \\
(33.8)\end{array}$ & $\begin{array}{l}-0.0131 \\
(-0.3)\end{array}$ & $\begin{array}{l}1.0122 \\
(25.4)\end{array}$ & $\begin{array}{l}0.7967 \\
(35.6)\end{array}$ & $\begin{array}{l}0.2155 \\
(4.7)\end{array}$ \\
\hline
\end{tabular}

trade's price change that is reversed during the subsequent 5 minutes. The average 5-minute reversal for each of our categories is reported in Table VII. Highly similar results emerge when the window is reduced to 1 minute or extended to 10 minutes.

Overall, all reversal averages are significantly different from zero. The average reversal is around 0.8. Given the nature of trading in the CBOT futures pit, these averages are economically sensible. The effective bid-ask spread of the CBOT T-Bond futures pit is generally less than one price tick. This implies that when the price moves, it almost always does so by just one tick. Large purchases move the price up one tick, while large sales move it down a tick. Therefore, short-run prices are extremely mean reverting. When the price-setting trade results in a continuation ( $\mathrm{RC}$ or $\mathrm{CC}$ ), the reversal is significantly larger than one tick, indicating that continuations are generally reversed after several minutes.

Examining price-setting trades that contract the trader's existing position, we see little difference between the reversals that follow trades set by traders with morning losses and those with morning gains. The range is from -0.07 to 0.20 and the average (weighted according to frequency) is -0.01 , although none of the differences are statistically significant. This implies that, relative to the average price 5 minutes into the future, traders with morning losses do not 
unwind their positions at significantly worse prices than those with morning gains.

If we focus on the price-setting trades of traders that expand their existing positions a different picture emerges. During the 5 minutes that follow their trades, traders with no morning losses witness a similar reversal in price to that of traders closing out their positions. However, traders with morning losses experience a significantly larger price reversal. Their trades reverse between 0.15 and 2.04 ticks more than those with no morning loss. All but the CR category achieves statistical significance. Across all position-expanding pricesetting trades, traders with morning losses see their trades reverse 0.22 more than those with no morning loss. This means that a trader with morning losses will see, on average, his price-setting trade reverse $27 \%$ more over the following 5 minutes than that placed by a trader with no morning loss.

The results of Table VII make it clear that the prices set by traders with losses in the morning are reversed much more dramatically than those set by traders with gains in the morning. Using estimates from this and the previous section, we can now perform some simple calculations to gauge the possible impact of biases on prices. We find that the average trader with morning losses places approximately $25 \%$ more price-setting trades than an equivalent trader with morning gains. We also find that traders with morning losses experience price reversals that are 27\% larger than the reversals of other traders. Thus, the increased price-setting trades placed by losing traders appear to be completely offset by their reduced price impact. Whether this is the case at the aggregate level is a question we address later.

The above results lead to several important inferences. First, because the trades of losing traders have only a temporary impact on prices, other traders in the pit appear to regard them as noise trades, and trade aggressively against them. Any impact of the traders' behavioral biases on prices appears to be rapidly eliminated by other market participants. Interestingly, the differences are only pronounced for traders expanding their positions. This implies that winning and losing traders are equally inclined to yield an edge when unwinding their positions and that the pit views these trades as equivalently uninformed. Other traders are therefore inclined to trade against unwinding winners and losers equally. It also highlights that when loss-averse traders are proactively taking on additional afternoon risk by expanding their positions that their price impact is ephemeral. The pit appears particularly eager to move against traders who expand their afternoon position in order to recover morning losses. Because the prices set by losing traders are reversed so dramatically, trading to make up morning losses is costly. Thus, Table VII provides strong evidence confirming that loss aversion is driving the behavior documented above.

\section{Aggregate Morning Losses and Afternoon Price Volatility}

In our final set of tests, we ask whether the price-setting trades executed by locals with morning losses cause afternoon prices to be more volatile than they 
would be if locals had no behavioral biases. This line of inquiry is prompted by the above trader level results, in which loss aversion leads on the one hand to greater afternoon risk-seeking and increased placement of price-moving trades, and on the other hand to increased reversal in prices set by traders attempting to make up morning losses. If the former effects dominate, we should see afternoon volatility increase following mornings with widespread losses. If the price reversals are most important, we should see little increase in afternoon volatility. ${ }^{21}$

Our measure of price volatility is the standard deviation of price changes measured at 1-second, 1-minute, 5-minute, 10-minute, and half-day frequencies. Like in our other regressions, we demean each measure of price volatility and normalize it by its standard deviation. To investigate our volatility hypothesis, we regress normalized afternoon volatility on the volatility in the corresponding morning and on several measures of the prevalence of morning losses among local traders. Specifically, our regressions are as follows:

$$
\sigma_{h, t}^{\mathrm{A}}=\alpha+\beta_{\sigma} \sigma_{h, t}^{\mathrm{M}}+\beta_{\lambda} \lambda_{t}^{\mathrm{M}}+\varepsilon_{t},
$$

where $\sigma_{h, t}^{\mathrm{A}}$ measures the abnormal volatility of afternoon price changes on date $t$ measured at frequency $h, \sigma_{h, t}^{\mathrm{A}}$ measures the abnormal volatility of morning price changes on date $t$ measured at frequency $h$, and $\lambda_{t}^{\mathrm{M}}$ measures aggregate morning losses on day $t$.

Measuring aggregate morning losses is not a simple task because it is not clear how losses should aggregate. Therefore, we choose several different ways to aggregate losses. First, we simply calculate the fraction of locals with losses at 11:00 a.m. Second, we calculate the average of $\pi_{i, t}^{\mathrm{M}}$ across traders each day. Since our regression relates aggregate risk to aggregate losses, the sample size is limited to the 236 trading days in our data. Also, because serial correlation may be a problem in our sample, all the estimates we report are adjusted to account for first-order autocorrelation. Neither average losses nor the fraction of traders with losses is significantly related to afternoon volatility at any frequency. Since none of these regressions produce significant results, we do not report the results in a table.

Neither of the measures described above considers the prevalence of losses among traders who are particularly loss-averse. Since there is substantial variation in the degree of loss aversion among traders, it is likely that measures of aggregate losses that consider which traders lose predict afternoon volatility more accurately. We construct two such measures by considering each trader's coefficients on morning profits in regressions (3) and (6). We consider a trader to be loss averse if his morning profit coefficient in equation (3) is negative (i.e., $\beta_{\pi}<0$ ). Thus, if a trader tends to take above-average afternoon total dollar risk when he has lost in the morning, he is classified as loss-averse. Using

\footnotetext{
${ }^{21}$ There may be other reasons to expect little increase in afternoon volatility following morning losses. Odean (1998b) predicts that when market makers are more overconfident and therefore more risk-tolerant, volatility should be lower. Grinblatt and Han (2002) find that a disposition effect can generate momentum in stock prices.
} 


\section{Table VIII}

\section{Aggregate Morning Losses and Afternoon Price Changes}

This table reports the results of a few time series regressions relating aggregate morning losses to the volatility of afternoon price changes. All regressions have the basic form,

$$
\sigma_{h, t}^{\mathrm{M}}=\alpha+\beta_{\sigma} \sigma_{h, t}^{\mathrm{M}}+\beta_{\lambda} \lambda_{t}^{\mathrm{M}}+\varepsilon_{t},
$$

where $\sigma_{h, t}^{\mathrm{A}}$ measures the volatility of afternoon price changes on date $t$ measured at frequency $h, \sigma_{h, t}^{\mathrm{A}}$ measures the volatility of morning price changes on date $t$ measured at frequency $h$, and $\lambda_{t}^{\mathrm{M}}$ measures the aggregate fraction of loss-averse traders with morning losses on day $t$. The aggregate fraction of loss-averse traders that have experienced morning losses on a given day is measured by taking traders whose coefficient $\beta_{\pi}$ is negative in equation (3) (or (6) for our second measure) and recording the fraction that have experienced a loss. The sample size is 236 trading days. All estimates are corrected for first-order autocorrelation, and $t$-statistics are in parentheses.

\begin{tabular}{|c|c|c|c|c|c|c|}
\hline \multirow[b]{2}{*}{ Frequency } & \multicolumn{3}{|c|}{$\begin{array}{c}\lambda_{t}^{\mathrm{M}}=\text { Fraction of } \\
\text { Loss-Averse Traders w/Losses }\end{array}$} & \multicolumn{3}{|c|}{$\begin{array}{c}\lambda_{t}^{\mathrm{M}}=\text { Fraction of } \\
\text { Loss-Averse Price Leaders w/Losses }\end{array}$} \\
\hline & $\alpha$ & $\beta_{\sigma}$ & $\beta_{\lambda}$ & $\alpha$ & $\beta_{\sigma}$ & $\beta_{\lambda}$ \\
\hline \multicolumn{7}{|c|}{ Dependent Variable: Abnormal Afternoon Volatility $\left(\sigma_{h, t}^{\mathrm{A}}\right)$} \\
\hline One second & $\begin{array}{l}-0.7 \\
(-1.99)\end{array}$ & $\begin{array}{l}0.4 \\
(6.73)\end{array}$ & $\begin{array}{l}2.09 \\
(2.01)\end{array}$ & $\begin{array}{l}-0.77 \\
(-2.07)\end{array}$ & $\begin{array}{l}0.39 \\
(6.67)\end{array}$ & $\begin{array}{l}2.37 \\
(2.09)\end{array}$ \\
\hline One minute & $\begin{array}{c}-0.62 \\
(-1.69)\end{array}$ & $\begin{array}{l}0.2 \\
(3.18)\end{array}$ & $\begin{array}{c}1.87 \\
(1.72)\end{array}$ & $\begin{array}{l}-0.86 \\
(-2.2)\end{array}$ & $\begin{array}{c}0.19 \\
(3.13)\end{array}$ & $\begin{array}{l}2.65 \\
(2.24)\end{array}$ \\
\hline Five minutes & $\begin{array}{c}-0.62 \\
(-1.75)\end{array}$ & $\begin{array}{c}0.31 \\
(5.09)\end{array}$ & $\begin{array}{l}1.90 \\
(1.8)\end{array}$ & $\begin{array}{l}-0.75 \\
(-1.98)\end{array}$ & $\begin{array}{l}0.3 \\
(4.96)\end{array}$ & $\begin{array}{l}2.34 \\
(2.03)\end{array}$ \\
\hline Ten minutes & $\begin{array}{c}-0.39 \\
(-1.06)\end{array}$ & $\begin{array}{c}0.23 \\
(3.72)\end{array}$ & $\begin{array}{c}1.17 \\
(1.08)\end{array}$ & $\begin{array}{l}-0.45 \\
(-1.15)\end{array}$ & $\begin{array}{c}0.23 \\
(3.64)\end{array}$ & $\begin{array}{c}1.39 \\
(1.17)\end{array}$ \\
\hline Half day & $\begin{array}{c}0.61 \\
(1.7)\end{array}$ & $\begin{array}{c}0.12 \\
(1.7)\end{array}$ & $\begin{array}{c}0.81 \\
(0.7)\end{array}$ & $\begin{array}{c}0.44 \\
(1.16)\end{array}$ & $\begin{array}{c}0.1 \\
(1.48)\end{array}$ & $\begin{array}{c}1.40 \\
(1.12)\end{array}$ \\
\hline
\end{tabular}

this, our measure of aggregate morning losses is simply the fraction of lossaverse traders that have experienced losses each morning. Similarly, using equation (6), we can consider a trader to be a loss-averse price leader if his morning profit coefficient in equation (6) is negative $\left(\beta_{\pi}<0\right)$ - that is, if he tends to make more price-setting trades when he has lost in the morning. Using this, we then measure aggregate morning losses as the fraction of lossaverse price leaders that have experienced losses each morning. We estimate equation (7) using both of these loss measures at each of the frequencies that we consider. The results are reported in Table VIII.

Table VIII contains evidence suggesting that afternoon price volatility is related to morning market maker profitability. Both measures of morning lossesthe fraction of loss-averse traders that are morning losers and the fraction of price leaders that are morning losers-yield similarly significant results. At the 1-second frequency, the coefficients are positive and significant in statistical and economic terms. A one standard deviation increase in the fraction of traders that are loss-averse losers (0.055) leads to an $11.5 \%$ increase in expected afternoon second-by-second volatility. This is consistent with the results in Table VI, since traders with morning losses place additional 
price-setting afternoon trades to assume additional risk. As we move to the 1- and 5-minute frequencies, the statistical and economic significance of the results remains approximately the same, with the price leader measure increasing in magnitude and the loss-averse measure declining. When volatility is measured over 10 minutes or over the entire afternoon, the results lose much of their economic significance, and as a result, all statistical significance. A one standard deviation decrease in the fraction of traders that are loss-averse losers now leads only to a $4.4 \%$ increase in overall afternoon volatility.

Consistent with Table VI, this result suggests that traders with morning losses create only short-term afternoon deviations from fundamentals. To see this, consider the impact on volatility of risk-seeking trades that have a temporary impact on prices in a setting where fundamentals follow a random walk. Measured over short horizons, the impact on volatility is likely to be large, as risk-seeking traders move prices considerably relative to fundamentals shocks. However, measured over longer horizons the risk-seeking trades are likely to be relatively less important for volatility, since the shocks to the true price process accumulate over time, but the price impact of the risk-seeking trades-because they lead to reversals-does not. Thus, although loss-averse traders may have a short-term influence on prices, consistent with the results in Table VI, their influence largely appears to have disappeared 10 minutes following their trades. However, it is important to note that while there appears to be a relationship between morning losses and afternoon volatility that is consistent with our earlier findings, the results are far from conclusive. Since our tests employ only a single observation per day, our regressions have limited power.

\section{Conclusion}

Although behavioral finance has recently become a rather popular area for asset pricing research, relatively little empirical evidence exists to directly support behavioral theories and assumptions. This is due in part to the fact that behavioral models cannot be tested as easily as traditional asset pricing models. Because aggregate consumption data or market returns data reflect the decisions of both rational and behaviorally biased traders, the standard tests of restrictions imposed by the Euler equations of rational, utility-maximizing agents are inapplicable. Proper assessment of behavioral theories requires detailed information on the trading strategies of various market participants, and until recently, such information has been difficult to come by.

This paper offers a detailed look at the trading behavior of a set of professional market makers and directly tests both for biases in their behavior and for the consequences such biases may have for prices. Our traders are highly proximate to the price-setting process and they generally close out their positions by the end of each trading day, providing a clean horizon over which they can evaluate their performance. These factors give us significant power to identify conditions under which behavioral biases are likely to be important in influencing prices. 
We find strong evidence that our traders are loss averse. They assume significantly more afternoon risk following morning losses than following morning gains. In their eagerness to assume greater afternoon risk, they place pricesetting trades more frequently, purchasing contracts at higher prices, and selling contracts at lower prices. However, afternoon prices set by traders with morning losses reverse substantially more than those set by traders with morning gains. This suggests that any price impact resulting from traders' behavioral biases dissipates extremely quickly. Consistent with this, we find that mornings with widespread losses lead to increases in short-run afternoon volatility but no increase in volatility measured over longer intervals.

Because of the nature of the data, market, and trader horizons, most of our power to detect effects on prices is concentrated at the microstructure level. In its focus on professional traders in a large and liquid capital market, our paper should be viewed as an exploration of the extent to which limits to arbitrage hold in such settings. Considering the speed with which the price effects of our loss-averse traders are reversed, limits to arbitrage do not appear to delay the elimination of behaviorally induced mispricing in our setting. Future work should investigate the extent to which this remains the case as trader horizons grow longer and prices are set with less liquidity.

\section{REFERENCES}

Allen, Franklin, 2001, Do financial institutions matter? Journal of Finance 56, 1165-1175.

Barberis, Nicholas C., and Ming Huang, 2001, Mental accounting, loss aversion, and individual stock returns, Journal of Finance 56, 1247-1292.

Barberis, Nicholas C., Ming Huang, and Tano Santos, 2001, Prospect theory and asset prices, The Quarterly Journal of Economics 116, 1-53.

Barberis, Nicholas C., Andrei Shleifer, and Robert W. Vishny, 1998, A model of investor sentiment, Journal of Financial Economics 49, 309-343.

Barberis, Nicholas C., and Richard Thaler, 2003, A survey of behavioral finance, in George Constantinides, Milton Harris, Rene Stulz, eds. Handbook of the Economics of Finance (North-Holland).

Benartzi, Shlomo, and Richard H. Thaler, 1995, Myopic loss aversion and the equity premium puzzle, Quarterly Journal of Economics 110, 73-92.

Camerer, Colin, Linda Babcock, George Loewenstein, and Richard Thaler, 1997, Labor supply of New York City cabdrivers: One day at a time, Quarterly Journal of Economics 112, 407-441.

Campbell, John, 2000, Asset pricing at the millennium, Journal of Finance 55, 1515-1567.

Chevalier, Judith, and Glenn Ellison, 1997, Risk taking by mutual funds as a response to incentives, Journal of Political Economy 105, 1167-1200.

Coval, Joshua D., and Tyler Shumway, 2001, Is sound just noise? Journal of Finance 56, 1887-1910.

Daniel, Kent, David Hirshleifer, and Avanidhar Subrahmanyam, 1998, Investor psychology and security market under- and overreactions, Journal of Finance 53, 1839-1885.

De Long, J. Bradford, Andrei Shleifer, Lawrence H. Summers, and Robert J. Waldmann, 1990, Noise trader risk in financial markets, Journal of Political Economy 98, 703-738.

Fama, Eugene F., 1965, The behavior of stock market prices, Journal of Business 38, 34-105.

Fama, Eugene F., and James D. MacBeth, 1973, Risk, return, and equilibrium: Empirical tests, Journal of Political Economy 71, 753-755.

Friedman, Milton, 1953, The case for flexible exchange rates, in Essays in Positive Economics (University of Chicago Press, Chicago).

Gervais, Simon, and Terrance Odean, 2001, Learning to be overconfident, Review of Financial Studies 14, 1-27. 
Grinblatt, Mark, and Bing Han, 2002, The disposition effect and momentum, Working paper, Anderson School at UCLA.

Hirshleifer, David, 2002, Investor psychology and asset pricing, Journal of Finance 56, 1533-1598.

Kahneman, Daniel, and Amos Tversky, 1973, On the psychology of prediction, Psychological Review 80, 237-25l.

Kahneman, Daniel, and Amos Tversky, 1979, Prospect theory: An analysis of decision under risk, Econometrica 47, 236-291.

Kahneman, Daniel, and Amos Tversky, 1992, Advances in prospect theory: Cumulative representation of uncertainty, Journal of Risk and Uncertainty 5, 297-323.

Kolb, Robert W., 1991, Understanding Futures Markets (Kolb Publishing, Miami).

Kuserk, Gregory J., and Peter R. Locke, 1993, Scalper behavior in futures markets-An empirical examination, Journal of Futures Markets 13, 409-431.

Langer, Ellen J., and Jane Roth, 1975, Heads I win, tails it's chance: The illusion of control as a function of the sequence of outcomes in a purely chance task, Journal of Personality and Social Psychology 32, 951-955.

Locke, Peter R., and Steven C. Mann, 1999, Do professional traders exhibit loss realization aversion? Working paper, Texas Christian University.

Manaster, Steven, and Steven C. Mann, 1996, Life in the pits: Competitive market making and inventory control, Review of Financial Studies 9, 953-975.

Miller, Dale T., and Mike Ross, 1975, Self-serving bias in attribution of causality: Fact or fiction? Psychological Bulletin 82, 213-225.

Odean, Terrance, 1998a, Are investors reluctant to realize their losses? Journal of Finance 53, 1775-1798.

Odean, Terrance, 1998b, Volume, volatility, price, and profit when all traders are above average, Journal of Finance 53, 1887-1934.

Odean, Terrance, 1999, Do investors trade too much? American Economic Review 89, 1279-1298.

Shefrin, Hersh, and Meir Statman, 1985, The disposition to sell winners too early and ride losers too long: Theory and evidence, Journal of Finance 40, 777-790.

Shiller, Robert J., 1981, Do stock prices move too much to be justified by subsequent changes in dividends? American Economic Review 71, 421-436.

Shiller, Robert J., 1989, Market Volatility (MIT Press, Cambridge).

Shumway, Tyler, 1998, Explaining returns with loss aversion, Working paper, University of Michigan Business School.

Thaler, Richard H., and Eric J. Johnson, 1990, Gambling with the house money and trying to break even: The effects of prior outcomes on risky choice, Management Science 36, 643-660.

Tversky, Amos, and Daniel Kahneman, 1971, Belief in the law of small numbers, Psychological Bulletin 76, 105-110.

Tversky, Amos, and Daniel Kahneman, 1974, Judgment under uncertainty: Heuristics and biases, Science 185, 1124-1131. 